\title{
Integrating adsorption and diffusion in nanopores using thermodynamics and Equations of State
}

DOI:

10.1021/acs.iecr.9b02379

\section{Document Version}

Accepted author manuscript

Link to publication record in Manchester Research Explorer

\section{Citation for published version (APA):}

Babaei, M., \& Seng, M. C. Y. (2019). Integrating adsorption and diffusion in nanopores using thermodynamics and Equations of State. Industrial \& Engineering Chemistry Research. https://doi.org/10.1021/acs.iecr.9b02379

\section{Published in:}

Industrial \& Engineering Chemistry Research

\section{Citing this paper}

Please note that where the full-text provided on Manchester Research Explorer is the Author Accepted Manuscript or Proof version this may differ from the final Published version. If citing, it is advised that you check and use the publisher's definitive version.

\section{General rights}

Copyright and moral rights for the publications made accessible in the Research Explorer are retained by the authors and/or other copyright owners and it is a condition of accessing publications that users recognise and abide by the legal requirements associated with these rights.

\section{Takedown policy}

If you believe that this document breaches copyright please refer to the University of Manchester's Takedown Procedures [http://man.ac.uk/04Y6Bo] or contact uml.scholarlycommunications@manchester.ac.uk providing relevant details, so we can investigate your claim.

\section{OPEN ACCESS}




\title{
Integrating adsorption and diffusion in nanopores using thermodynamics and Equations of State
}

\author{
Masoud Babaei ${ }^{*}$, Mark Chong Yun Seng ${ }^{1}$ \\ ${ }^{1}$ School of Chemical Engineering and Analytical Science, The University of Manchester, M13 9PL, Manchester, \\ UK
}

\section{Abstract}

In the orders of nanometres, diffusion and adsorption effects deviate significantly from current conventional models which result in limited estimation accuracy of hydrocarbons capacity and recovery potential. At such small pore sizes, limited pore space as well as wall superimposition effects affect both adsorption and diffusion behaviour. Classical laboratory experiments carried out on nanoporous material are unable to characterise adsorption behaviour accurately due to the presence of larger macropores within the network. At present, grand-canonical Monte Carlo (GCMC) molecular simulations are usually employed to model both diffusion and adsorption effects independently. However, this method is computationally expensive and does not provide a quantitative variation trend of adsorption isotherm with pore size. In this paper, a thermodynamics-based Two-Dimensional Equation of State (2-D EoS) model is introduced to characterise adsorption isotherms in small carbon and mineral capillaries. The effects of pore sizes on adsorption isotherm parameters are compared with that determined from a bulk scale predictive model. Regressed parameters from pure component isotherms are applied to a methane-carbon dioxide binary system. Results are consistent with that determined from molecular simulations. Therefore, it is concluded that by applying appropriate cubic equation of state, the 2-D EoS Adsorption Isotherm Model is able to produce an accurate quantitative representation of the adsorption behaviour in nanopores. Finally, thermodynamic factor (the correction factor for diffusivity for pure and binary component) is calculated directly from adsorption isotherms. The thermodynamic factor was also shown to have the ability to calculate diffusion coefficient without considering the type of transport mechanism.

\section{1 - Introduction}

Unconventional petroleum reserves such as shale gas and coal bed methane (CBM) have attracted much attention and commercial interests in the recent years due to depletion of conventional resources and growing energy demands. This is also coupled with the advances in drilling and fracturing technology that allows extraction of hydrocarbons from these reserves to be technically and economically feasible. Shale gas is produced by horizontal drilling and hydraulic fracturing of shale

\footnotetext{
* Corresponding author: Telephone +44 (0)161 306 4554, email: masoud.babaei@ manchester.ac.uk
} 
rock that has a high organic content. On the other hand, coal bed methane refers to hydrocarbons that are trapped within unminable coal seams. Currently, the methane is extracted by drilling into the coal seams followed by the pumping of groundwater, allowing a reduction in the reservoir pressure and thus, displacement of methane from the coal ${ }^{1}$. Global technically recoverable CBM and shale gas reserves are estimated to be 79 and 188 trillion cubic metres, with a recovery factor ranging from 10 to $30 \%$. This value is much lower than that of conventional gas, which can reach up to $80 \%{ }^{1,2,3,4}$.

Although unconventional energy reserves have reached commercial maturity, carbon dioxide $\left(\mathrm{CO}_{2}\right)$ emissions reduction technologies or $\mathrm{CO}_{2}$ capture and storage (CCS) strategy are lagging behind in terms of development due to the lack of commercial benefits. Current global $\mathrm{CO}_{2}$ stands at 36 billion tons per year and in order to maintain global warming below $2^{\circ} \mathrm{C}$, growth in greenhouse gas emissions has to be stopped by 2020 and a $60 \%$ decrease in the global emissions has to be achieved by $2050^{5,6}$. Recent studies suggest that methane extraction can be enhanced by injecting $\mathrm{CO}_{2}$ into both shales and coal seams. The adsorption/desorption process allows the displacement of methane $\left(\mathrm{CH}_{4}\right)$ from the coalbed seams while acting as a permanent storage of $\mathrm{CO}_{2}$ in the coalbed and thus, allowing it to be an effective CCS technology ${ }^{7}$. Global gas shales and coal seams reserves have a geological storage potential of 740 and 488 Gigatonnes of $\mathrm{CO}_{2}$ respectively ${ }^{8}$. Such technology, if found to be commercially viable, is a win-win situation where there will be an increase in hydrocarbon recovery potential as well as a reduction to the net global greenhouse gas emissions. In these reserves, hydrocarbons are generally stored as dissolved gas in the organic matrix, free gas within pores and adsorbed gas to the walls ${ }^{9}$.

Based on the International Union of Pure and Applied Chemistry (IUPAC), nanopores can be divided into three categories based on the size diameter, which are macropores (diameter $>50 \mathrm{~nm}$ ), mesopores (diameter $2-50 \mathrm{~nm}$ ) and micropores (diameter $<2 \mathrm{~nm}$ ) (9). Research into the pore size distributions of both shale and coal show that micropores and mesopores contribute to $70-82 \%$ of the total pores ${ }^{10,11}$. The large surface area to volume ratio of these small pores greatly enhances the surface for adsorption, with about $50-80 \%$ of the natural gas trapped as an adsorbed phase in the reservoir ${ }^{12}$. In such a small pore, diffusion is significantly affected by the adsorbed layer due to density and viscosity variations within the cross-section of the pore and this results in a deviation of the behaviour from continuumbased theory models ${ }^{13,14}$. Therefore, this limits the accuracy of the recovery potential of the reserves.

Since it is impossible to carry out classical experiments on small nanopores, diffusion behaviours and adsorption isotherms in nanopores are often determined by computationally expensive grand-canonical Monte Carlo (GCMC) molecular simulations. Adsorption results from the simulations are normally expressed in terms of total loadings or excess loadings against pressure or fugacity due to the difficulty in determining the exact boundary between the bulk and adsorbate phase ${ }^{13,14}$. Therefore, this results in the inability to use conventional adsorption models such as Langmuir monolayer or Brunauer-EmmettTeller (BET) multilayer adsorption model because these models utilise absolute adsorption to define 
adsorption isotherms. Some previous investigations have fitted Type 1 isotherms that are expressed in terms of total loadings with the Langmuir model ${ }^{15,13}$. However, such fit is fundamentally inappropriate as total loading is not equivalent to absolute adsorption. Besides, the use of Langmuir model will require the following assumptions to be valid: (i) monolayer adsorption within pores; (ii) constant saturation capacity for all components; (iii) enthalpy of adsorption constant with loading; and (iv) negligible interactions between adsorbed molecules. However, such behaviour is not observed in nanopores $^{16,17}$.

In a recent investigation, an empirical mathematical model has been developed to calculate absolute adsorption in clay nanopores from the component density profile in the nanopore, excess adsorption and adsorbed phase volume. Results from the investigation show that at high pressures, the discrepancy in the calculated and the actual value only differs by $3 \%{ }^{18}$. With the value of absolute adsorption calculated, it allows the fitting of conventional parametric isotherms. However, empirical and kinetics-based model may not be applicable in a nano-scale as there are other factors such as walls superimposition effect and constrained pore space that is dependent on the pore size. These effects are not observed in bulk scale adsorption. Therefore, in this paper, a thermodynamics-based TwoDimensional Equation of State (2-D EoS) approach is used to fit the adsorption isotherms of nanopores. The advantage of a thermodynamics-based model compared to kinetics model is the ability to take into account all adsorption isotherms without any assumptions as it relies only on the chemical equilibrium between the free gas phase and the adsorbate phase, which is a principal criterion for adsorption ${ }^{19}$. In comparison with other thermodynamics-based models such as ideal adsorbed solution theory, the 2-D EoS shows better result in fitting the adsorption isotherms in bulk scale adsorption models in coal at high pressures up to $120 \mathrm{bar}^{20}$. Besides, it has the ability to be a predictive model for coal systems, which is not applicable for ideal adsorbed solution theory. 2-D EoS adsorption isotherm parameters can also be predictively calculated based on the Ono-Kondo Lattice Theory model, using Lennard-Jones interaction parameters ${ }^{21,22}$. In addition, non-ideal mixing effects in a multicomponent system can be conveniently taken into account with the 2-D EoS using suitable equation of states mixing rules ${ }^{19}$.

\section{Aims and Objectives}

This paper aims to introduce a thermodynamics-model, known as a Two-Dimensional Equations of State (2-D EoS) adsorption model to quantify adsorption in nanopores. The adsorption isotherm parameters obtained are used to determine the thermodynamic factors for the adsorption system. It should be noted that diffusion is the only contributing mechanism to mass transfer in nanopores and there is a significant adsorbed phase in nanopores, which causes a behavioural deviation of the diffusion characteristic from normal bulk diffusivity ${ }^{15}$. Therefore, thermodynamic factors play an important role in predicting diffusion behaviour in a nanopore by correlating diffusivity in nanopores to that of Fick's diffusivity. By examining the impact of pore sizes on the isotherm parameters as well 
as the thermodynamic factor, it is possible that adsorption and diffusion effects for different sizes of nanopores can be accurately predicted based on bulk scale values, reducing the need for molecular simulations. In this paper we (i) determine the applicability of the 2-D EoS approach for adsorption in nanopores, (ii) we focus on the impact of pore size on the adsorption isotherm parameters, and (3) the 2-D EoS adsorption model is employed for a binary system of $\mathrm{CH}_{4}-\mathrm{CO}_{2}$ from pure component adsorption isotherms parameters.

\section{2 - Theoretical basis}

Two-Dimensional Equations of State (2-D EoS) approach has been introduced by Payne et al. ${ }^{23}$, compared with experiments by Glandt et $a l^{24}$, and explored for both pure component and binary mixture adsorption system ${ }^{19,25,26,27}$. The generalized 2-D EOS is analogous to the three-dimensional equation of state, by simply replacing pressure with the spreading pressure, and volume with the

surface $\operatorname{area}^{28}$.Parameters obtained for the pure component adsorption isotherms can then be used in a binary system to investigate quantitatively the adsorption characteristic of one component in the presence of other components by employing appropriate mixing rules.

\subsection{2-D EoS adsorption model for pure component}

Gibbs Representation is the fundamental theory underlying the 2-D EoS Adsorption Model. In a real adsorption system, the volume of the system consists of three components which are the solid, the adsorbed layer and the bulk fluid. However, it is often difficult to identify the region in which the fluid is adsorbed to the surface or free-moving. Therefore, Gibbs Representation simplifies the real adsorption system by associating the adsorbed phase to an imaginary surface, known as the Gibbs Dividing Surface (GDS). This reduces the volume of the system into two parts whereby there is only solid phase and the bulk fluid phase, with the GDS acting as a barrier between the two phases. This allows the adsorbed layer to be treated as a two-dimensional phase with its unique thermodynamic properties $^{29,30}$. Similar to a conventional three-dimensional (3-D) fluid where the thermodynamic properties can be calculated from conventional cubic equations of state (3-D EoS) such as PengRobinson EoS, the thermodynamic properties of the 2-D adsorbed layer can also be calculated from a modified cubic equation of state ${ }^{19}$. A generalised form of the 2-D equation of state based on the compressibility factor of the adsorbate, $Z$ has been derived and presented as Eq. (1), where $T$ is the temperature of the adsorbate ${ }^{31} . \eta, \lambda$ and $\varepsilon$ are EoS dependent parameters where the values are tabulated in Table 1 whereas $\alpha$ and $\beta$ are analogous parameters to $a$ and $b$ in a conventional 3-D EoS. Also $R$ is the ideal gas constant.

$$
Z=\frac{\sigma}{\sigma-\beta}-\frac{\alpha \sigma / R T}{T^{\varepsilon}(\sigma+\eta \beta)(\sigma+\lambda \beta)}
$$


The primary criterion of adsorption is that at equilibrium, the chemical potential of the adsorbate phase is equal to that of the bulk liquid or vapour phase. In terms of fugacity, the fugacity of the adsorbate layer, $f_{i}^{a}$ can be quantitatively related to the fugacity of the bulk phase $f_{i}^{g}$ by Henry's Constant, $k$ as shown in Eq. (2), where $k$ is the slope of the adsorption isotherm at the origin ${ }^{19} . f_{i}^{a}$ can then be quantitatively related to $Z$ based on Eq. (3).

$$
\begin{aligned}
f_{i}^{a} & =k R T f_{i}^{g} \\
\ln f_{i}^{a} & =\int_{\sigma}^{\infty}(Z-1) \frac{d \sigma}{\sigma}+Z-1+\ln \frac{R T}{\sigma}
\end{aligned}
$$

By incorporating Eqs. (1), (2) and (3), fugacity can be obtained as Eq. (4) and (5). Four EoS's are being investigated in this work, which are van der Waals (vdW), Redlich-Kwong (RK), SoaveRedlich-Kwong (SRK) and Peng-Robinson (PR). Eq. (4) is used for the vdW EoS and Eq. (5) is applied for the remaining three EoS's ${ }^{32}$.

$$
\begin{aligned}
f_{i}^{g} & =\frac{1}{k(\sigma-\beta)} \exp \left[\frac{\beta}{\sigma-\beta}-\frac{2 \alpha}{\sigma R T}\right] \\
f_{i}^{g} & =\frac{1}{k(\sigma-\beta)} \exp \left[\frac{\beta}{\sigma-\beta}-\frac{\alpha}{\beta R T^{1+\varepsilon}}\left(\frac{1}{\eta-\lambda} \ln \left(\frac{\sigma+\eta \beta}{\sigma+\lambda \beta}\right)+\frac{\sigma}{(\sigma+\eta \beta)(\sigma+\lambda \beta)}\right)\right]
\end{aligned}
$$

Table 1. Parameter for Equations of States ${ }^{32,19}$.

\begin{tabular}{lcccc}
\hline & \multicolumn{3}{c}{ Parameters } & \multirow{2}{*}{ Ref. } \\
\cline { 2 - 4 } Equations of State & $\boldsymbol{\varepsilon}$ & $\boldsymbol{\eta}$ & $\boldsymbol{\lambda}$ & \\
\hline Redlich - Kwong (RK) & 0.5 & 1 & 0 & 33 \\
Soave - Redlich - Kwong (SRK) & 0 & 1 & 0 & 34 \\
Peng - Robinson (PR) & 0 & $1+\sqrt{2}$ & $1-\sqrt{2}$ & 35 \\
\hline
\end{tabular}

\subsection{2-D EoS adsorption model for binary system}

The pure component adsorption isotherms can be expanded to a binary system by applying the generalised equation for the calculation of fugacity of a particular component in a multicomponent system, as shown in Eq. (6). In this formulation, the Lewis-Randall rule is used to calculate the fugacity of each component in the mixture. Based on the Lewis-Randall rule, fugacity of a component in a mixture is equal to the product of its mole fraction in the mixture and the pure component fugacity at the same pressure and temperature conditions of the mixture. Conventional van der Waals one-fluid 
mixing rules as shown in Eqs. (7), (8) and (9) are also being incorporated into the formulation to account for unlike interactions between the two components in the adsorbate phase $\mathrm{e}^{36,37,38}$.

$$
\begin{aligned}
\ln f_{i}^{a} & =\int_{\sigma}^{\infty}\left[\left(\frac{\partial\left(n^{a} Z\right)}{\partial n_{i}^{a}}\right)_{T, A, n_{j}^{a}}-1\right] \frac{d \sigma}{\sigma}+\ln \frac{x_{i} R T}{\sigma} \\
\alpha_{m} & =x_{1}^{2} \alpha_{1}+2 x_{1} x_{2} \alpha_{12}+x_{2}^{2} \alpha_{2} \\
\alpha_{12} & =\left(1-k_{12}\right) \sqrt{\alpha_{1} \alpha_{2}} \\
\beta_{m} & =x_{1} \beta_{1}+x_{2} \beta_{2}
\end{aligned}
$$

By applying similar methodology as shown in Section 2.1, the properties of component 1 in the binary component adsorbate layer can also be related to the bulk phase fugacity, $f_{1}^{g}$. It is however, more convenient to express the equation in terms of mole fraction in the bulk phase, $y_{1}$ based on the fact that $f_{1}^{g}=P \phi_{1} y_{1}$, where $\phi_{1}$ is the fugacity coefficient of the component 1 .

$$
\begin{aligned}
y_{1}= & \frac{x_{1}}{k_{1} P \phi_{1}\left(\sigma-\beta_{m}\right)} \exp \left[\frac{\beta_{1}}{\sigma-\beta_{m}}-\frac{2}{\sigma R T}\left(\alpha_{1} x_{1}+\alpha_{12} x_{2}\right)\right] \\
y_{1}= & \frac{x_{1}}{k_{1} P \phi_{1}\left(\sigma-\beta_{m}\right)} \exp \left[\left(\frac{\beta_{1}}{\sigma-\beta_{m}}\right)-2\left(\frac{\alpha_{1} x_{1}+\alpha_{12} x_{2}}{(\eta-\lambda) \beta_{m} R T^{1+\varepsilon}}\right) \ln \frac{\sigma+\eta \beta_{m}}{\sigma+\lambda \beta_{m}}\right. \\
& \left.\quad-\frac{\alpha_{m} \beta_{1}}{\beta_{m} R T^{1+\varepsilon}}\left(\frac{\sigma}{\left(\sigma+\eta \beta_{m}\right)\left(\sigma+\lambda \beta_{m}\right)}-\frac{1}{\beta_{m}(\eta-\lambda)} \ln \frac{\sigma+\eta \beta_{m}}{\sigma+\lambda \beta_{m}}\right)\right]
\end{aligned}
$$

\subsection{Thermodynamic factors}

Although the Fick's diffusivity, $D_{t}$, has shown great success in quantifying diffusion rates based on the concentration gradient of components $\nabla c$, these are often limited to bulk fluids where confinement effects are not significant. When fluid is trapped within a small confined conduit such as a nanopore, the walls create an adsorptive force field, resulting in a radial concentration gradient. As opposed to Fick's diffusivity where the values for a specific component is often determined by experiments, molecular simulations are often employed to model and investigate the diffusion effect in nanopores. This is due to the infeasibility of carrying out an experiment on such a small scale. However, in molecular simulations, chemical potential gradients are used to create the diffusion effect instead of the concentration gradient ${ }^{39,40,41,42}$. Therefore, diffusivity in nanopores is often expressed in terms of Maxwell-Stefan diffusivity, $D_{c}$. In order to correlate both terms and correct the Fick's diffusivity to Maxwell-Stefan diffusivity, the term thermodynamic correction factor, $\Gamma$ is used, where $\Gamma=$ $\partial \ln \left(f_{i}^{g}\right) / \partial \ln \left(c^{a}\right)^{43}$. As previously mentioned, determination of an accurate value of $\Gamma$ is important as 
it allows the direct calculation of the corrected diffusivity value, $D_{c}$, from known experimental Fick diffusivity values, $D_{t}$, as shown in Eq. (12). Since the concentration of the adsorbate, $c^{a}$, is the inverse of the molar surface area, $\sigma$, for a pure component adsorption system the thermodynamic factor can be expressed in terms of $f_{g}$ and $\sigma$ equivalent to that of the 2-D EoS isotherm as presented in Eq.(4) and (5).

$$
\begin{aligned}
D_{t} & =D_{c} \times \Gamma \\
c^{a} & =\frac{1}{\sigma} \\
\Gamma & =\frac{\partial \ln \left(f_{i}^{g}\right)}{\partial \ln \left(c^{a}\right)}=\frac{c^{a}}{f_{i}^{g}} \frac{\partial f_{i}^{g}}{\partial c^{a}}=-\frac{\sigma}{f_{i}^{g}} \frac{\partial f_{i}^{g}}{\partial \sigma}
\end{aligned}
$$

For a binary system, the thermodynamic factor can be affected by the presence of other components. The fugacity of both components, $f_{1}^{g}$ and $f_{2}^{g}$ can affect both concentration of component 1 in the adsorbate, $x_{1}$, and amount of adsorbate per unit area, $c^{a}$. Therefore, Eq. (15) involving both terms have to be employed to calculate the thermodynamic factor, $\Gamma_{11}$.

$$
\Gamma_{11}=\left.\frac{\left(x_{1} c^{a}\right)}{f_{1}^{g}} \frac{\partial f_{1}^{g}}{\partial\left(x_{1} c^{a}\right)}\right|_{f_{2}^{g}}
$$

\section{3 - Methodology}

\subsection{Fugacity, absolute adsorption, excess adsorption and density}

As molecular simulations are not carried out in this work, data used for the regression of the adsorption isotherms are obtained from published journals on molecular simulations of adsorption and diffusion in nano-capillaries commonly found in shale and coals seams ${ }^{13,44,45}$. This includes the use of a hypothetical three-layer carbon nano-capillary as an adsorbent to model kerogen in nanopores as well as minerals related capillaries such as quartz, kaolinite and chlorite for minerals in coal bed systems. As adsorption isotherms that are investigated in this research involve components at high absolute pressure conditions up to 300 bar, fugacity values have to be calculated in order to obtain an accurate adsorption isotherm suitable for the 2-D EoS. The fugacity values for the bulk phase are calculated based on Peng-Robinson cubic equation of state ${ }^{35}$. In our study, total pressure or partial pressure are expressed as bulk pressures (i.e. pressures of the bulk fluid), and total pressure or partial pressure are expressed as bulk pressures.

Most molecular simulations quantify adsorbate amount in terms of total loading and excess loading. Total loading is the total amount of molecules present in the nanopore, without considering whether 
the molecules are in the bulk or the adsorbate phase. Excess loading, on the other hand, is defined as the excess amount present in the actual nanopore compared to a hypothetical nanopore where there are no adsorption effects, as illustrated in Figure 1. Absolute adsorption, $m_{a b s}$, which is the actual amount adsorbed to the walls can be calculated based on the general Eq. (16), where $m_{e x}$ is the excess adsorption, $\rho_{b}$ is the bulk density and $V_{a}$ is the volume occupied by the adsorbate.

$$
m_{a b s}=m_{e x}+\rho_{b} V_{a}
$$

Most components, including inert gases such as argon, show a two-layer adsorption above 50 atm, where there are two peaks on the density profile curve ${ }^{15,13}$. The higher peak represents the first adsorbed layer closer to the wall while the second lower peak is the second adsorbed layer. Density profiles from most molecular simulations have shown that $V_{a}$ stays relatively constant with pressure and pore $\operatorname{sizes}^{18}$. Based on the research carried out by Tian et al. ${ }^{18}$, the determination of $V_{a}$ can be simplified by taking into account the volume of the first layer only, which is shown as A-B and $\mathrm{A}^{\prime}-\mathrm{B}^{\prime}$ region in Figure 1. However, in this investigation, there is an exception for methane in carbon nanocapillaries at pressures above $90 \mathrm{~atm}$, due to the formation of a third layer of adsorption ${ }^{15,13}$. Therefore, under these conditions, $V_{a}$ is defined as the volume occupied by both the first and second adsorbed layers. The value of bulk densities, $\rho_{b}$ are determined from the Peng-Robinson cubic equation of state.

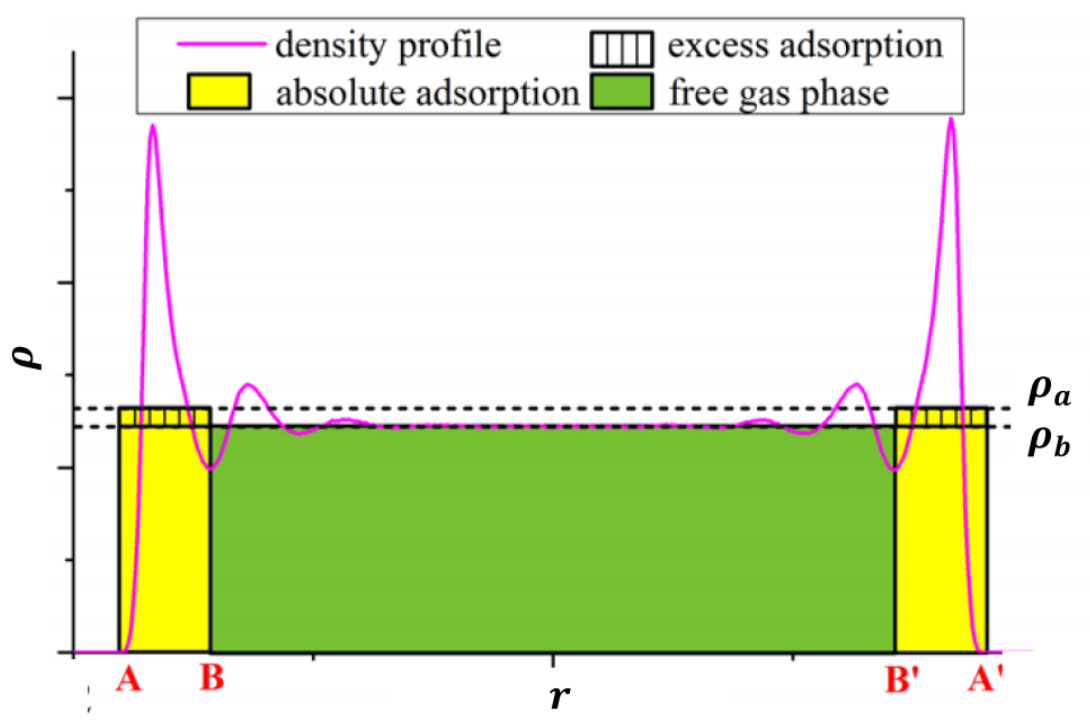

Figure 1. Schematic representation of adsorption density profile in a nanopore ${ }^{18}$.

In some of the molecular simulations data obtained for this work, the units of absolute adsorption are expressed in terms of mol (kg adsorbate) ${ }^{-1}$. In order to apply the 2-D EoS adsorption isotherm, units of the absolute adsorption have to be expressed in terms of number of moles per unit area, which require a detailed calculation of the specific surface area of multi-walled capillaries. For this purpose, we use $S S A_{M W N T}$ based on 


$$
S S A_{M W N T}=\frac{S S A_{S W} \cdot d_{e}}{n d_{e}-2 d_{S-s}\left[\sum_{i=1}^{n-1} i\right]}
$$

where $S S A_{S W}$ is the specific surface area if the material is laid in a single-wall sheet, $d_{e}$ is the external diameter of the nanotube, $n$ is the number of walls in the multi-walled nanotube and $d_{s-s}$ is the adjacent distance between the layers within the nanotube wall ${ }^{46}$. Taking conventional three-walled carbon nanotube as an example, the value of specific surface area of a graphene sheet, $S S A_{S W}$ is 2630 $\mathrm{m}^{2} \mathrm{~g}^{-1}, d_{s-s}$ is $0.335 \mathrm{~nm}$ and $n$ is $3^{47,13}$.

\subsection{Regression parameters}

The regression parameters for the 2-D Equations of State adsorption isotherm are determined through a continuous iteration model on General Algebraic Modelling System (GAMS) Software Version 24.6.1. The objective function of the solver is set to minimise value of the relative error, $S_{M}$, shown as Eq. (18), by regressing the adsorption isotherm parameters, $\alpha, \beta$ and $k$. The calculated fugacities, $f_{i}^{c a l}$, are calculated from Eqs. (4) and (5) using the values of molar surface area, $\sigma$, and compared with the

corresponding experimental fugacity value, $f_{i}^{e x p}$. Solver used in this non-linear programming (NLP) was CONOPT Version 3.17A. Next, the values of average absolute deviation (AAD) and root-meansquare-error (RMSE) are calculated based on Eqs. (19) and (20) to assess the performance of different equations of state used for the iteration. Figure 2 portrays the exact steps involved in the iteration procedure.

$$
\begin{aligned}
S_{M} & =\sum_{i=1}^{N_{p}}\left[\frac{f_{i}^{c a l}-f_{i}^{\text {exp }}}{f_{i}^{\text {exp }}}\right]^{2} \\
A A D(\%) & =\frac{100}{N_{p}} \sum_{i=1}^{N_{p}} \frac{\left|f_{i}^{c a l}-f_{i}^{\text {exp }}\right|}{f_{i}^{\text {exp }}} \\
R M S E & =\sqrt{\frac{1}{N_{p}}\left(f_{i}^{\text {cal }}-f_{i}^{\text {exp }}\right)^{2}}
\end{aligned}
$$




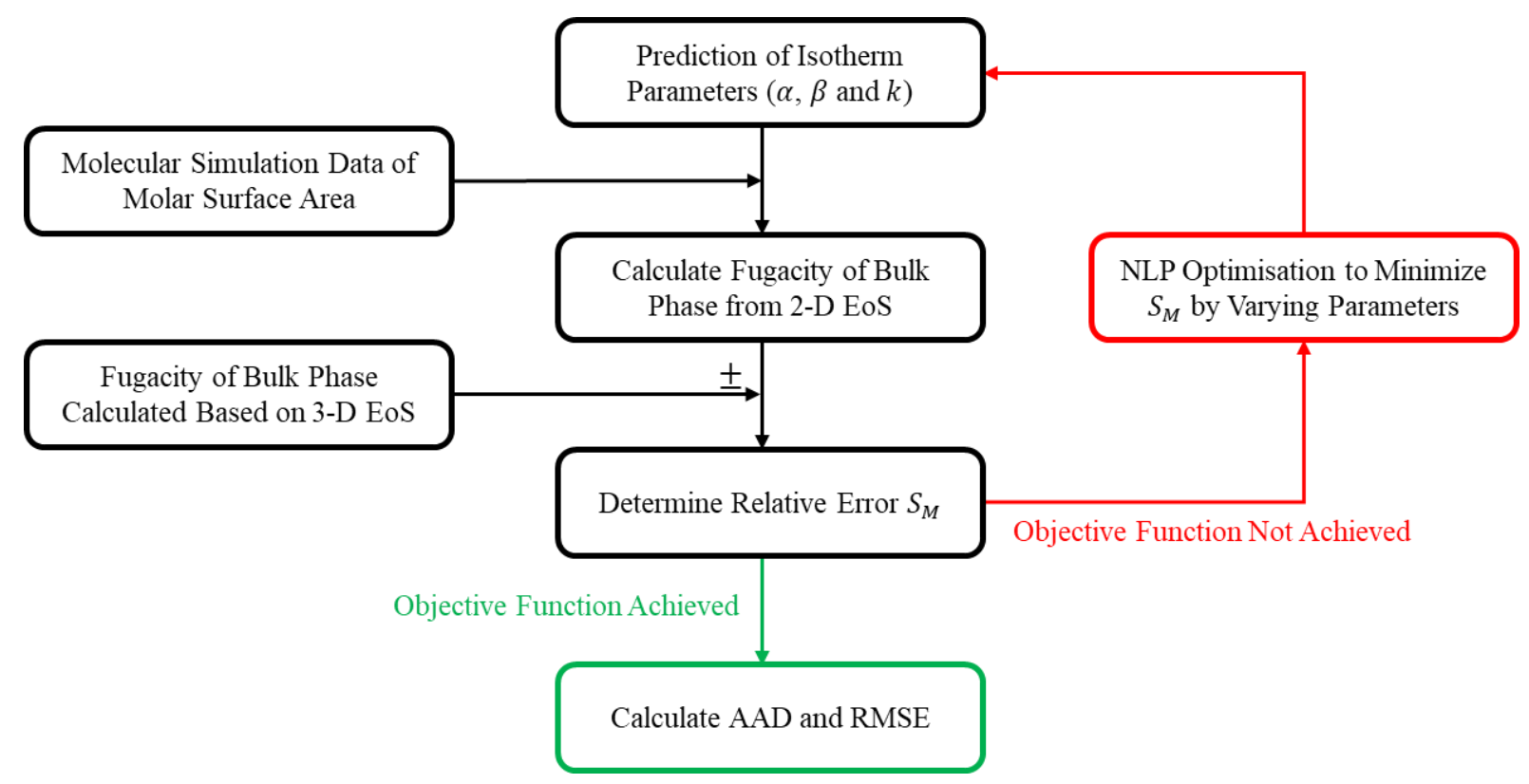

Figure 2. Iterative procedure for determination of regression parameters.

In order to prevent topology traps within the optimisation procedure, starting points (initial guesses) for the iteration process are $10^{-8} \mathrm{~mol} \mathrm{bar}^{-1} \mathrm{~m}^{-2}$ for the $k$ value, $10^{9} \mathrm{~kg} \mathrm{~m}^{4} \mathrm{~mol}^{-2} \mathrm{~s}^{-2}$ for $\alpha$ and $10^{5} \mathrm{~m}^{2} \mathrm{~mol}^{-1}$ for $\beta$. Scaling factors to revise $k$ and $\alpha$ values are employed in some cases where domain error is resulted due to large variables that have exceeded the built-in tolerance of GAMS. Regression parameters are then used with the 2-D EoS pure component adsorption isotherm Eqs. (4) and (5) to plot graphs for visual investigation of the fitted parameters. The regression parameters for the adsorption isotherms are only applicable within the fugacity values region used for the optimisation regression procedure. Range of molar surface area values, $\sigma$, used for the graph plots are between $10^{4}$ and $10^{7} \mathrm{~m}^{2} \mathrm{~mol}^{-1}$ with step sizes of $100 \mathrm{~m}^{2} \mathrm{~mol}^{-1}$.

Average relative standard deviation $(A R S D)$ values are calculated based on Eq. (21) to compare the differences in the values of the three regressed adsorption isotherm parameters obtained from the four EoS, where $\sigma_{x}$ and $\bar{x}$ are the standard deviation and mean value of the parameters determined from different EoS, respectively. Calculation of $A R S D$ allows the determination of whether a specific parameter depends heavily on the type of EoS used.

$$
\operatorname{ARSD}(\%)=\frac{100}{N_{p}} \sum_{x=1}^{N_{p}} \frac{\sigma_{x}}{\bar{x}}
$$

\subsection{Adsorption isotherms for binary system}

The regressed parameters calculated from pure component adsorption isotherms are used for the determination of adsorption isotherms in a binary system. Regressed data for pure component adsorption isotherms that are used for the simulation of binary adsorption isotherms are obtained from 
the same source. This ensures consistency where molecular structure of adsorbent and molecular simulation method used for both components are identical. A summary of the iterative procedure used in the determination of binary adsorption isotherms from pure component isotherms is illustrated in Figure 3.

The first step is the specification of the range of pressures, $P$, and the mole fraction of each component, $y_{1, \text { spec }}$ and $y_{2, \text { spec }}$, for the calculation of both components' fugacity coefficients, $\phi_{1}$ and $\phi_{2}$. Then, the values of molar surface area, $\sigma$, and mole fraction of component $1, x_{1}$ are estimated. The mole fraction of component 2, $x_{2}$ is calculated based on the fact that the summation of $x_{1}$ and $x_{2}$ must equal to 1 . By applying the three pre-determined 2-D EoS pure component parameters and the binary mixing parameter, $k_{12}$, into Eqs. as Eqs. (6) to (9), the mole fraction of both components, $y_{1, \text { calc }}$ and $y_{2, \text { calc }}$ in the bulk phase can be calculated. These calculated values are then compared with the bulk component mole fractions specified previously, $y_{1, \text { spec }}$ and $y_{2, \text { spec }}$. The objective function is to ensure that the difference in the bulk component mole fractions value specified and calculated are identical with constraints that the individual mole fractions value are the same.

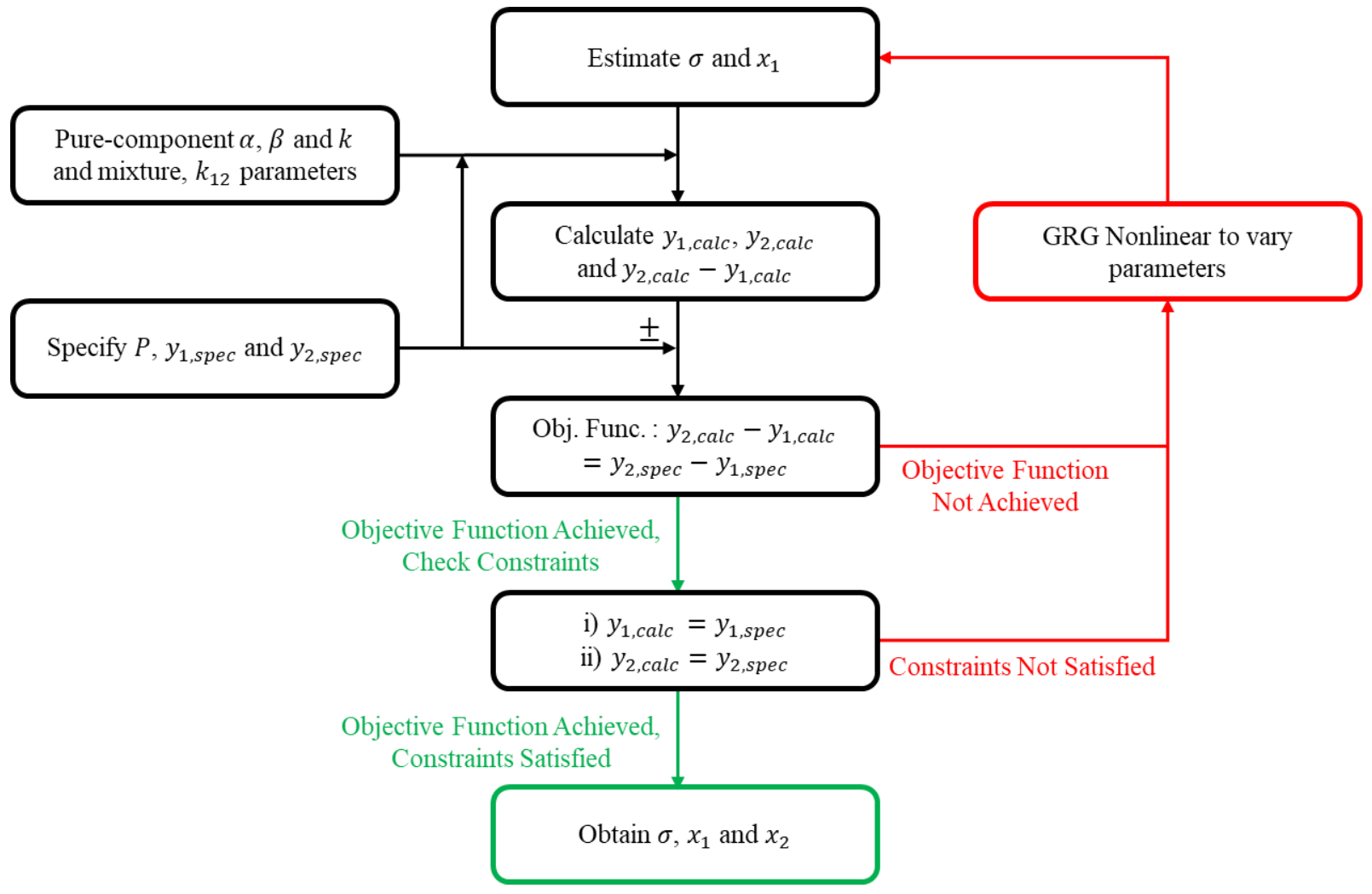

Figure 3. Iterative procedures for determination of binary system adsorption isotherms

A Visual Basic for Applications code is used to solve for each plot automatically until the objective functions for all plots have achieved for the 2-D EoS being investigated. In order to prevent topology traps, starting points for $x_{1}$ and $\sigma$, are set to be close to the final result, which are about 0.5 and $10^{5}$ respectively. 
This work is focused on the $\mathrm{CH}_{4}-\mathrm{CO}_{2}$ binary system. The binary interaction parameter, $k_{12}$, for the $\mathrm{CH}_{4}-\mathrm{CO}_{2}$ system is assumed to be equivalent of the cubic EoS $\mathrm{CH}_{4}-\mathrm{CO}_{2}$ binary interaction parameter, which is $0.0919^{48,49}$. The relatively small $k_{12}$ value is due to the non-polarity of both $\mathrm{CH}_{4}$ and $\mathrm{CO}_{2}$ components, resulting in weak van der Waals forces existing between the two components only.

\subsection{Ono-Kondo Lattice Theory model}

Researchers managed to establish a predictive model to calculate the 2-D EoS adsorption isotherms in a bulk scale activated carbon and coal system ${ }^{21,22}$. This model is based on the Ono-Kondo Lattice Theory model which treats the fluid system using layers of lattice cells that can be filled or unfilled and is applicable in both mono and multi-layer adsorption prediction ${ }^{50}$. By incorporating the model into a 2-D EoS adsorption isotherm, the three parameters $\alpha, \beta$ and $k$ can be predicted from Eqs. (22) to (27). Although this model is derived for bulk scale adsorption systems, this paper focuses on the applicability of such a model on nanopores. It should be noted in this Ono-Kondo model, all parameters are independent of pore sizes.

Constants involved in the equations are $N_{a}, k_{B}$ and $R$, which are Avogadro's constant, Boltzmann's constant and universal gas constant, respectively. The density of carbon adsorbent, $\rho_{S}$, is $0.382 \AA^{-2}$ and the thermal expansion coefficient of methane, $\gamma$, is assumed to be $0.0024 \mathrm{~K}^{-1(21)} \cdot \rho_{m c}$ is defined as the maximum adsorbate phase density, which can either be assumed to be the density of methane at normal boiling point or the reciprocal of van der Waals' co-volume. $\sigma_{m, 0}^{\prime}$ is the maximum surface density of adsorbate at the fluid boiling point under atmospheric pressure, $T_{0}$. Lennard-Jones Potential parameters, which are potential well depths, $\varepsilon_{f f}{ }^{*}$ for fluid molecule and $\varepsilon_{s s}{ }^{*}$ for solid molecule as well as collision diameters, $\sigma_{f f}$ and $\sigma_{s s}$, are tabulated in Table 2 .

$$
\begin{aligned}
\alpha & =\left(0.432 N_{a}^{2} \pi \varepsilon_{f f}{ }^{*} \sigma_{f f}^{2}-\frac{2 N_{a}^{2} \pi \rho_{s} \varepsilon_{f s} \sigma_{f s}^{4}}{3}\right) \\
\varepsilon_{f s} & =\frac{6}{5} \pi \rho_{s} \sigma_{f s}^{2} \sqrt{\varepsilon_{f f}{ }^{*} \varepsilon_{s s}{ }^{*}} \\
\sigma_{f s} & =\frac{\sigma_{f f}+\sigma_{s s}}{2} \\
\beta & =\exp \left(\gamma T-\gamma T_{0}-\ln \sigma_{m, 0}^{\prime}\right)
\end{aligned}
$$




$$
\begin{aligned}
\sigma_{m, 0}^{\prime} & =\frac{1}{\left[\frac{3 \sqrt{3}}{2}\left(\frac{\sigma_{f f}}{2}\right)^{2} N_{a}\right]} \\
k & =\frac{1}{\beta \rho_{m c} R T} \exp \left(-\frac{\varepsilon_{f s}}{k_{B} T}\right)
\end{aligned}
$$

Table 2. Parameters for Ono-Kondo model ${ }^{21,22}$.

\begin{tabular}{ccccc}
\hline \multirow{2}{*}{ Components } & \multicolumn{4}{c}{ Parameters } \\
\cline { 2 - 5 } & $\left(\boldsymbol{\varepsilon}_{f f}{ }^{*} / \boldsymbol{k}_{\boldsymbol{B}}\right) / \mathbf{K}$ & $\left(\boldsymbol{\varepsilon}_{s s}{ }^{*} / \boldsymbol{k}_{\boldsymbol{B}}\right) / \mathbf{K}$ & $\boldsymbol{\sigma}_{f f} / \AA$ & $\boldsymbol{\sigma}_{s s} / \AA$ \\
\hline Methane & 148.6 & - & 3.758 & - \\
Carbon & - & 28 & - & 3.4 \\
\hline
\end{tabular}

\subsection{Thermodynamic factor}

Based on the pure component 2-D adsorption isotherm equations as presented in Section 2.1, an algebraic equation for the differential equation required for the calculation of thermodynamic factor as presented in Section 2.3 can be obtained. Due to the complexity of Eqs (4) and (5), the algebraic differential equations are determined from the differentiation function built in the Symbolic Math Toolbox $^{\text {TM }}$ software within MATLAB R2017a. Therefore, this allows the plot of a real curve of thermodynamic factor against fugacity. Although an absolute differential equation can be obtained for pure component adsorption system, such a method is not applicable in a binary or multi-component system. This is due to the fact that in a binary system, the adsorbed amount and the mole fraction of components in the adsorbate are both affected by the fugacities of both components. For example, in a binary system, component 1 adsorbed amount can be affected by the bulk phase fugacity of component 2 although bulk phase fugacity of component 1 is kept constant. Therefore, a numerical differentiation technique is applied to obtain the thermodynamic factor.

The flowchart for the binary system thermodynamic factor calculation is presented in Figure 4 . The process is carried out on MATLAB R2017a with regressed parameters determined from the pure component isotherms inputted into the code. Both values of molar surface area, $\sigma$, and mole fraction of component $1, x_{1}$, are varied to determine the corresponding value of bulk components fugacity of component 1 and $2, f_{1}^{g}$ and $f_{2}^{g}$, respectively, by using equations expressed in Section 2.2. Values of molar surface area, $\sigma$, ranged between $10^{4}$ and $10^{7} \mathrm{~m}^{2} \mathrm{~mol}^{-1}$ with step sizes of $100 \mathrm{~m}^{2} \mathrm{~mol}^{-1}$ while for each value of $\sigma$, mole fraction of component $1, x_{1}$, are varied between 0 and 1 with a step size of 0.001. It is worth noting that following the Lewis-Randall Rule, fugacity of a component 1 in the 
mixture is related to its mole fraction in the mixture, total pressure of the mixture and the pure component fugacity coefficient by equation $f_{1}^{g}=y_{1} P \phi_{1}$, and the same applies for component 2 .

If the thermodynamic factor of component $1, \Gamma_{11}$ has to be determined, then the fugacity of component $f_{2}^{g}$ would be rounded off to three decimal places. It is assumed that due to the small variation in the value of $f_{2}^{g}$, the impact towards the adsorption of component 1 is negligible. Then, the value of $f_{1}^{g}$ is sorted from smallest to largest as well for constant rounded-off $f_{2}^{g}$. In order to calculate the thermodynamic factor as defined $f_{1}^{g}$ value using Eq. (15), the differential term is calculated based on the numerical difference in the two adjacent points for amount of adsorbed component $1, x_{1} c^{a}$, and the corresponding $f_{1}^{g}$ value.

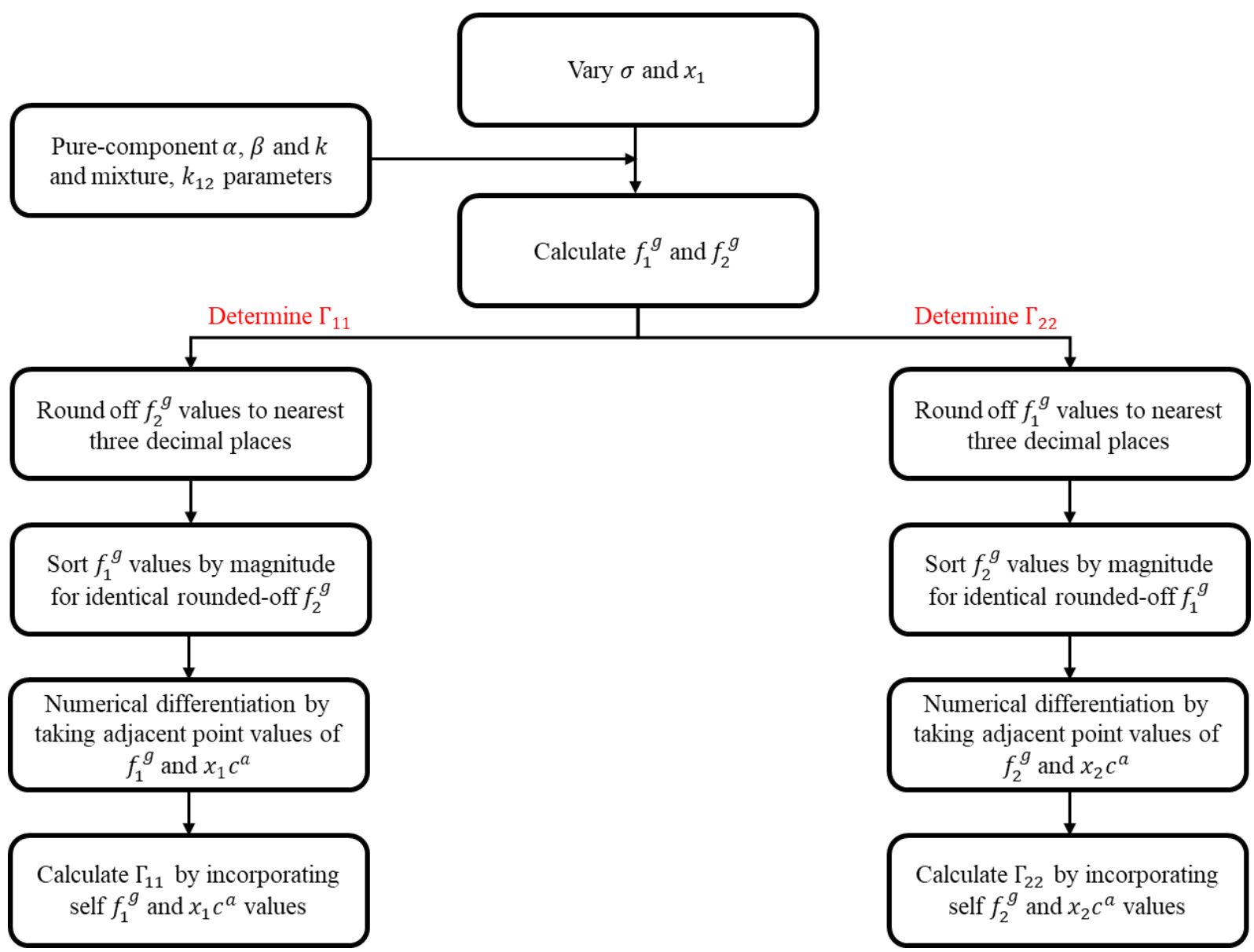

Figure 4. Determination of thermodynamic factor for binary component system.

\section{4 - Results and discussion}

\subsection{Regression parameters}

Table 3 presents the overall AAD and RMSE for the fugacity values calculated using the pure component adsorption isotherms investigated and regressed in this research. Based on the table, it is found that all the four EoSs being investigated in this research are able to fit the pure component 
adsorption isotherm data in a nanopore with great accuracy, with an average absolute deviation ranging of about 5.5\%. It should also be noted that the 2-D EoS is based on a thermodynamics model and not from a kinetic approach i.e. Langmuir Model. Therefore, this avoids the need to consider the adsorption behaviour occurring in the pore. In fact, the enthalpy of adsorption varies significantly in nanopores and is a function of the adsorbate loading. At high pressures close to saturation pressure, the enthalpy of adsorption increases exponentially due to increasing repulsive forces ${ }^{17}$. Additionally, it is observed that there is a strong deviation in the general potential energy distribution curves at pore sizes smaller than $3 \mathrm{~nm}^{45}$. As the adsorption behaviour within nanopores is a function of pore sizes and pressure, thermodynamics-based 2-D EoS will be a more appropriate candidate to fit molecular simulation data for adsorption in nanopores.

Table 3 Summary of AAD and RMSE for fugacity values.

\begin{tabular}{lcc}
\hline Equations of State & $\boldsymbol{A A D} / \%$ & $\boldsymbol{R} \boldsymbol{M S E} / \mathbf{b a r}$ \\
\hline van der Waals (vdW) & 5.31 & 17.13 \\
Redlich - Kwong (RK) & 5.63 & 18.86 \\
Soave - Redlich - Kwong (SRK) & 5.53 & 18.86 \\
Peng - Robinson (PR) & 5.60 & 18.87 \\
\hline
\end{tabular}

Generally, van der Waals (vdW) EoS portrays the best performance with the lowest AAD and RMSE value as compared to the other three EoS, as portrayed in Table 3. However, it can also be observed that the average absolute deviation (AAD) values do not vary heavily with the type of EoS being used, as shown in Table 4. On close investigation, the regressed parameters for $k$ and $\beta$ values are also found to be independent to the type of equation of state being applied. Taking the regressed parameters from the four EoS for the same adsorption system, the average standard deviation of the parameters from the mean value are calculated. The average standard relative deviation of both $k$ and $\beta$ values are calculated to be $4.08 \%$ and $2.30 \%$ respectively, proving the fact that these two values are independent on the type of EoS being used for regression. This also confirms previous research findings on bulk scale adsorbents such as activated carbon and molecular sieve zeolites ${ }^{19,32}$.

Based on the Ono-Kondo Lattice Theory model, $\beta$ is related to the maximum molar surface area or the inverse of the maximum adsorption capacity, which depends on the diameter of the pore and the adsorbent - adsorbate interactions. Therefore, $\beta$ does not vary heavily on the type of EoS being applied $21,22,32$. On the other hand, $k$ is related to the slope of adsorption isotherm at the origin, or infinitesimally small pressure, such value only takes into account the strength of adsorbent-adsorbate interactions with negligible adsorbate-adsorbate interactions. This is due to at such low pressures, the bulk phase can be assumed to be ideal with negligible intermolecular interactions ${ }^{19,21}$. On the other hand, the value of $\alpha$ is defined from the bulk phase intermolecular interactions, adsorbate intermolecular interactions as well as adsorbate - adsorbate interactions. Out of the three parameters, this is the only parameter that takes into account bulk component intermolecular interactions. Since 
various cubic EoS have different methodologies and assumptions used in accounting the non-idealities of fluid, this resulted in a large deviation of $\alpha$ values for different EoS, as tabulated in Table 4. In particular, $\alpha$ parameters obtained from Redlich-Kwong (RK) equation of state are 10 to 100 orders of magnitude larger than the remaining three EoS. This is due to the difference in the power of the temperature term on Eq. (5) where RK has a power of 1.5 whereas other equations of state have a power of 1. However, it is also worth noting that $\alpha$ parameters for both Soave-Redlich-Kwong (SRK) and Peng-Robinson (PR) are close to each other, with the average relative standard deviation of both values standing at $6.1 \%$.

In cubic systems, SRK and PR equations of state can actually predict phase equilibrium and account for high pressure high temperature fluids close to critical conditions, where both vdW and RK equations of state are not applicable ${ }^{51,52}$. Comparative studies carried out between SRK and PR EoS on various conditions have also shown that there are no significant differences in their performances at various conditions and this is why both of these EoS are still widely used till now ${ }^{53,54}$. Therefore, although SRK and PR equations of state have a slightly larger overall AAD value compared to vdW, it should be the preferred EoS for regression due to the fact that it can take into account bulk phase liquid and supercritical conditions.

\subsection{Impact of pore size on 2-D EoS adsorption isotherm parameters}

This section discusses on the influence of pore size on the 2-D EoS adsorption isotherm parameters. The average absolute deviation (AAD) values for each of the regressed adsorption isotherms are not shown as the average deviation is only about 5.3\%, which shows a good fit of the parameters. It should be noted that adsorption behaviour in nanopores can be affected by several factors including the available pore volume for adsorption, the superimposition effect by both walls within the capillary as well as pressure. Adsorbate investigated in this section is methane with different adsorbents commonly found in coal bed, which are mineral capillaries (quartz, montmorillonite, illite, kaolinite and chlorite) and carbon capillaries with different oxygen: carbon atomic ratios of 1:4 (C4), 1:10 (C10) and 1:20 (C20). Then, parameters obtained are compared with those obtained via the 2-D EoS predictive model based on the Ono-Kondo Lattice Theory model ${ }^{21,22}$. This allows the validation of such predictive model on nanopores.

In the initial findings, it is found that all materials, the value of $k$ and $\beta$ determined from the four EoS are approximately the same, with the average relative standard deviation of values at $4.29 \%$ and 1.62 $\%$, respectively. This result is in concordant with the results found in Section 4.1. Therefore, only parameters determined from PR EoS are presented in this section such that it is consistent with the predictive combined 2-D EoS and Ono-Kondo model. Parameters determined from the remaining three EoS, which are vdW, RK and SRK are found to have similar trends to that of PR. 


\subsection{1. $\beta$ parameter}

The $\beta$ parameter is often regarded as the reciprocal of the maximum surface density of the adsorbed phase $^{21}$. Based on previous research carried out, if the adsorption isotherm approaches that of a Langmuir model whereby there is only monolayer adsorption, $\beta$ can be defined as the surface area over the saturation capacity of monolayer ${ }^{32}$. Based on Figure $5(a)$, it is observed that apart from mineral nano-capillaries at pore size of $1 \mathrm{~nm}, \mathrm{C} 20$ and quartz nano-capillaries at pore sizes more than $15 \mathrm{~nm}$, the remaining nano-capillaries have similar values of $\beta$ falling along the general trend and with similar values throughout the graph. Although mineral capillaries are weaker adsorbents as compared to carbon-based nano-capillaries, the results show that $\beta$ is not affected by the strength of interaction between the solid and the adsorbate molecules. Therefore, the result is consistent with the Ono-Kondo Lattice Theory model.

It is also found that for all materials at pore sizes above $1.5 \mathrm{~nm}$, the value of $\beta$ generally increases with pore size until it reaches a point before it begins to plateau or decrease slightly. This trend has proved that the maximum surface density of the adsorption layer decreases with increasing pore size. A possible explanation for such effect is due to the superimposition effect contributed by the pore walls ${ }^{10}$. At small pore diameters, density of adsorption layer on the wall is increased due to the additional solidfluid interactive forces exerted by the opposing wall. Thus, this increases the maximum capacity that can be adsorbed on the wall and decreases the $\beta$ value. These interactions can also be explained by the average isosteric enthalpy of adsorption, where the value decreases exponentially with increasing pore size. The decrease in the enthalpy is due to the increasing pore size that resulted in a reduction in the superimposition effect ${ }^{45}$. The percentage of increase in the $\beta$ value as pore sizes increases ranges between $51.7 \%$ and $78.2 \%$, with the average at $61.7 \%$. This is consistent with the percentage decrease in the average enthalpy of adsorption of approximately $60 \%$ as the pore sizes increase from $1 \mathrm{~nm}$ to 20 $\mathrm{nm}^{45}$.

As previously mentioned, the Ono-Kondo Lattice Theory model has the ability to predict the 2-D adsorption isotherm parameters for a bulk scale adsorption system and based on the equations, the $\beta$ value is calculated to be approximately $8.55 \times 10^{4} \mathrm{~m}^{2} \mathrm{~mol}^{-1}$ for methane, as illustrated in Figure 5(a) ${ }^{21,22}$. As the pore diameter increases, $\beta$ values of most capillaries approaches the Ono-Kondo predicted value, with the exception of $\mathrm{C} 20$ and quartz. This is likely to be due to the poor fitting of the adsorption parameters. Since percentage or absolute error in the molecular simulation data was not provided by the authors who have carried out the simulations, error in the adsorption parameters cannot be determined. However, it can generally be seen that at pore size of $15 \mathrm{~nm}$, the $\beta$ values have increased to that of the predicted Ono-Kondo Lattice Theory model. Since the Lattice Theory model only considers a single surface adsorption on a bulk scale, this indicates that the superimposition effect has become negligible at pore sizes above $15 \mathrm{~nm}$. 
From Figure 5(a), it can also be observed that there is a sharp increase in the value of $\beta$ when the pore size decrease from $1.5 \mathrm{~nm}$ to $1 \mathrm{~nm}$. It is also surprising to see that this value is larger than the maximum value within the general trend, which is found at pore sizes within 15 to $20 \mathrm{~nm}$ region. However, such a phenomenon is not observed for carbon-based nano-capillaries, the general trend observed for all materials at pore sizes more than $1.5 \mathrm{~nm}$ is extended to $1 \mathrm{~nm}$ for these capillaries. This signifies that for carbon nano-capillaries, the superimposition effect is enhanced at pore size of $1 \mathrm{~nm}$ but other factors may influence the adsorption behaviour in mineral capillaries of the same pore size.

A close investigation into the density profile and molecular arrangement in the $1 \mathrm{~nm}$ adsorption system shown in Figure 6 reveals that for organic pores, C4, C10 and C20, methane molecules are accumulated at the region close to the pore walls. In mineral pores, the accumulation occurs at regions further away from the walls. This is due to the weaker attractive interactions and stronger repulsive interactions between the minerals in the pore walls and the methane molecules. Since the adsorption layer forms further away from the pore, the actual pore volume available for adsorption in a $1 \mathrm{~nm}$ mineral pore is considerably smaller than an equivalent diameter organic pore. In other words, a mineral pore with an area of $1 \mathrm{~m}^{2}$ will have a smaller pore space for adsorption compared to an organic pore with the same area. Therefore, from the data analysis, it is found that although the methane adsorption capacity increases with decreasing pore size, this is only true if the pore space is not limiting as both opposing walls exert a stronger attractive force on the adsorbent. 
Table 4. Regressed parameters for 2-D EoS models and performance of different EoS for pure gas adsorption systems.

\begin{tabular}{|c|c|c|c|c|c|c|c|c|c|c|c|c|c|c|c|c|c|c|c|c|}
\hline \multirow{2}{*}{ Ads. } & \multirow{2}{*}{$\begin{array}{c}T / \\
\mathrm{K}\end{array}$} & \multirow{2}{*}{$\begin{array}{c}f_{g} / \\
\text { bar }\end{array}$} & \multirow{2}{*}{$\begin{array}{l}d / \\
\mathrm{nm}\end{array}$} & \multicolumn{4}{|c|}{$10^{8} k / \mathrm{mol} \mathrm{bar}^{-1} \mathrm{~m}^{-2}$} & \multicolumn{4}{|c|}{$10^{-9} \alpha^{(*)}$} & \multicolumn{4}{|c|}{$10^{-5} \beta / \mathrm{m}^{2} \mathrm{~mol}^{-1}$} & \multicolumn{4}{|c|}{$\boldsymbol{A A D} / \%$} & \multirow{2}{*}{$\begin{array}{c}\text { Ref. } \\
(+)\end{array}$} \\
\hline & & & & vdW & $\mathrm{RK}$ & SRK & PR & vdW & RK & SRK & PR & vdW & $\mathrm{RK}$ & SRK & PR & vdW & RK & SRK & PR & \\
\hline \multirow{2}{*}{$\mathrm{Ar}$} & \multirow{6}{*}{300} & $10-$ & 2 & 4.79 & 4.25 & 4.25 & 4.03 & 0.57 & 25.45 & 1.47 & 1.71 & 1.58 & 1.56 & 1.56 & 1.56 & 11.97 & 12.74 & 12.74 & 12.93 & \multirow{6}{*}{13} \\
\hline & & 290 & 4 & 6.21 & 6.36 & 6.36 & 6.56 & -0.38 & -11.90 & -0.69 & -0.72 & 0.00 & 0.21 & 0.21 & 0.24 & 6.89 & 6.63 & 6.63 & 6.33 & \\
\hline \multirow{2}{*}{$\mathrm{CH}_{4}$} & & $10-$ & 2 & 18.02 & 18.22 & 18.22 & 18.43 & -0.10 & -4.01 & -0.23 & -0.26 & 0.94 & 0.95 & 0.95 & 0.95 & 7.91 & 7.89 & 7.89 & 7.87 & \\
\hline & & 224 & 4 & 14.16 & 14.52 & 14.52 & 14.57 & 0.07 & 2.10 & 0.12 & 0.13 & 0.55 & 0.53 & 0.53 & 0.53 & 10.63 & 10.18 & 10.18 & 10.05 & \\
\hline \multirow{2}{*}{$\mathrm{Ne}$} & & $10-$ & 2 & 1.35 & 1.33 & 1.33 & 1.31 & 0.37 & 13.65 & 0.79 & 0.86 & 1.53 & 1.45 & 1.45 & 1.43 & 9.64 & 9.87 & 9.87 & 10.03 & \\
\hline & & 380 & 4 & 1.74 & 1.76 & 1.76 & 1.75 & 0.27 & 9.39 & 0.54 & 0.59 & 1.80 & 1.73 & 1.73 & 1.71 & 14.50 & 14.27 & 14.27 & 14.25 & \\
\hline $\mathrm{CH}_{4}$ & \multirow[b]{2}{*}{350} & $\begin{array}{l}19- \\
270\end{array}$ & \multirow[b]{2}{*}{2} & 7.73 & 7.67 & 7.67 & 7.61 & 0.07 & 2.69 & 0.14 & 0.15 & 0.35 & 0.33 & 0.33 & 0.33 & 1.56 & 1.60 & 1.60 & 1.63 & \multirow[b]{2}{*}{44} \\
\hline $\mathrm{CO}_{2}$ & & $\begin{array}{l}19- \\
141\end{array}$ & & 11.11 & 10.49 & 10.49 & 10.11 & 0.13 & 5.20 & 0.28 & 0.31 & 0.21 & 0.20 & 0.20 & 0.19 & 4.99 & 4.76 & 4.76 & 4.58 & \\
\hline \multirow{10}{*}{$\mathrm{CH}_{4}$} & \multirow{10}{*}{333} & \multirow{10}{*}{$\begin{array}{l}19- \\
306\end{array}$} & 1 & 26.19 & 24.67 & 24.67 & 23.91 & 0.11 & 5.33 & 0.29 & 0.34 & 0.62 & 0.61 & 0.61 & 0.61 & 1.63 & 1.65 & 1.65 & 1.65 & \multirow{10}{*}{45} \\
\hline & & & 1.5 & 16.21 & 14.54 & 14.54 & 13.70 & 0.24 & 11.37 & 0.62 & 0.73 & 0.65 & 0.64 & 0.64 & 0.64 & 6.36 & 6.63 & 6.63 & 6.66 & \\
\hline & & & 2 & 15.44 & 13.78 & 13.78 & 12.93 & 0.26 & 12.03 & 0.66 & 0.77 & 0.65 & 0.63 & 0.63 & 0.63 & 6.42 & 6.84 & 6.84 & 6.88 & \\
\hline & & & 3 & 17.88 & 16.46 & 16.46 & 15.67 & 0.21 & 9.65 & 0.53 & 0.62 & 0.66 & 0.65 & 0.65 & 0.65 & 7.72 & 7.85 & 7.85 & 7.87 & \\
\hline & & & 4 & 15.70 & 14.10 & 14.10 & 13.21 & 0.28 & 12.92 & 0.71 & 0.83 & 0.72 & 0.70 & 0.70 & 0.70 & 9.88 & 10.15 & 10.15 & 10.17 & \\
\hline & & & 6 & 14.07 & 16.76 & 12.01 & 11.09 & 0.34 & 11.85 & 0.90 & 1.06 & 0.77 & 0.73 & 0.76 & 0.76 & 8.53 & 8.57 & 8.80 & 8.81 & \\
\hline & & & 8 & 16.83 & 14.52 & 14.52 & 13.53 & 0.31 & 14.90 & 0.82 & 0.96 & 0.81 & 0.80 & 0.80 & 0.80 & 7.24 & 7.45 & 7.45 & 7.45 & \\
\hline & & & 10 & 15.45 & 13.50 & 13.50 & 12.59 & 0.32 & 15.44 & 0.85 & 0.99 & 0.83 & 0.82 & 0.82 & 0.82 & 11.87 & 11.98 & 11.98 & 11.99 & \\
\hline & & & 15 & 12.61 & 10.56 & 10.56 & 9.66 & 0.44 & 21.10 & 1.16 & 1.36 & 0.94 & 0.93 & 0.93 & 0.93 & 13.05 & 13.16 & 13.16 & 13.17 & \\
\hline & & & 20 & 12.25 & 10.44 & 10.44 & 9.51 & 0.44 & 20.93 & 1.15 & 1.36 & 0.98 & 0.96 & 0.96 & 0.97 & 14.11 & 14.19 & 14.19 & 14.21 & \\
\hline \multirow{10}{*}{$\mathrm{CH}_{4}$} & \multirow{10}{*}{333} & & 1 & 21.68 & 20.30 & 20.30 & 19.61 & 0.14 & 6.60 & 0.36 & 0.42 & 0.62 & 0.61 & 0.61 & 0.61 & 4.37 & 4.39 & 4.39 & 4.40 & \\
\hline & & & 1.5 & 18.64 & 17.30 & 17.30 & 16.56 & 0.18 & 8.44 & 0.46 & 0.54 & 0.63 & 0.62 & 0.62 & 0.62 & 4.71 & 4.97 & 4.97 & 5.01 & \\
\hline & & & 2 & 18.68 & 17.55 & 17.55 & 16.87 & 0.17 & 7.67 & 0.42 & 0.49 & 0.62 & 0.61 & 0.61 & 0.61 & 5.37 & 5.57 & 5.57 & 5.60 & \\
\hline & & & 3 & 16.71 & 15.53 & 15.53 & 14.84 & 0.21 & 9.33 & 0.51 & 0.60 & 0.66 & 0.65 & 0.65 & 0.65 & 6.30 & 6.50 & 6.50 & 6.53 & \\
\hline & & $19-$ & 4 & 15.76 & 14.49 & 14.49 & 13.78 & 0.23 & 10.59 & 0.58 & 0.68 & 0.68 & 0.67 & 0.67 & 0.67 & 7.36 & 7.62 & 7.62 & 7.65 & 45 \\
\hline & & 306 & 6 & 12.76 & 11.10 & 11.10 & 10.27 & 0.35 & 16.55 & 0.91 & 1.06 & 0.78 & 0.77 & 0.77 & 0.77 & 10.19 & 10.44 & 10.44 & 10.47 & \\
\hline & & & 8 & 12.26 & 10.71 & 10.71 & 9.88 & 0.38 & 17.65 & 0.97 & 1.14 & 0.83 & 0.82 & 0.82 & 0.82 & 12.31 & 12.62 & 12.62 & 12.64 & \\
\hline & & & 10 & 9.70 & 7.76 & 7.76 & 6.93 & 0.53 & 25.69 & 1.41 & 1.66 & 0.93 & 0.91 & 0.91 & 0.91 & 13.79 & 13.95 & 13.95 & 13.96 & \\
\hline & & & 15 & 6.61 & 4.79 & 4.79 & 4.13 & 0.74 & 36.97 & 2.03 & 2.40 & 1.06 & 1.04 & 1.04 & 1.04 & 17.32 & 17.61 & 17.61 & 17.60 & \\
\hline & & & 20 & 7.29 & 5.50 & 5.50 & 4.80 & 0.71 & 35.05 & 1.92 & 2.27 & 1.09 & 1.08 & 1.08 & 1.08 & 16.41 & 16.70 & 16.70 & 16.69 & \\
\hline
\end{tabular}

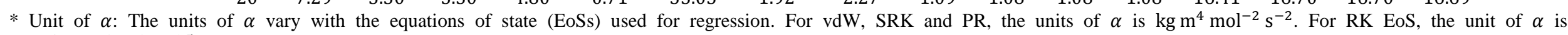
$\mathrm{kg} \mathrm{m}^{4} \mathrm{~mol}^{-2} \mathrm{~s}^{-2} \mathrm{~K}^{-0.5}$.

+ Additional Notes: Type and structure of adsorbent used in the molecular simulations of the adsorption system varies. Kazemi and Takbiri-Borujeni ${ }^{13}$ utilises a three-layered smooth carbon capillary composed of carbon atoms only, Kazemi and Takbiri-Borujeni ${ }^{44}$ simulates the system on a carbon capillary with rough surfaces where carbon atoms are removed from the three-layer wall at certain

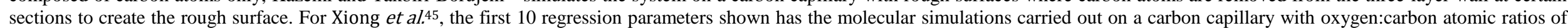
$1: 10$ while the next 10 parameters, molecular simulations were carried out on a capillary with 1:20 oxygen:carbon ratio. 


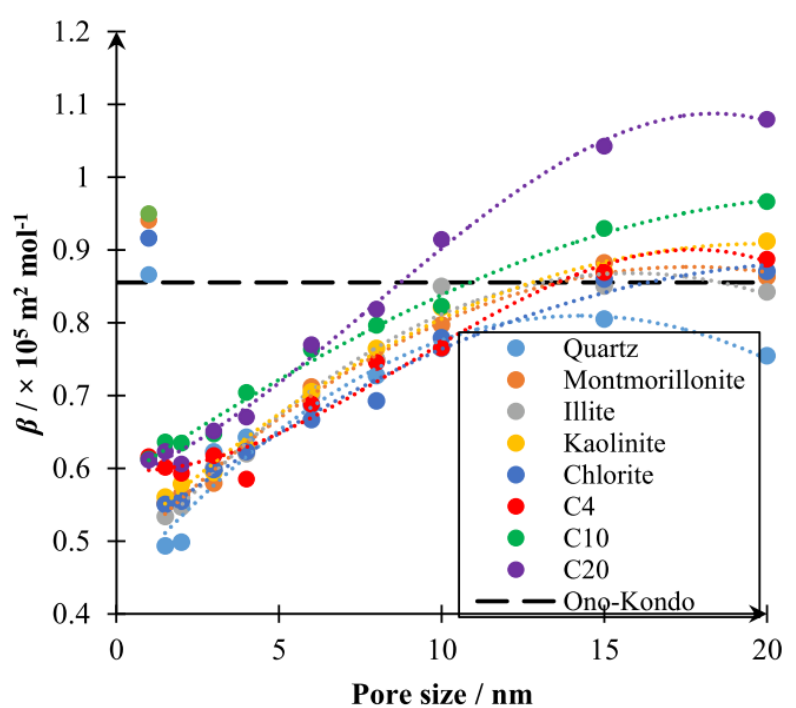

(a)

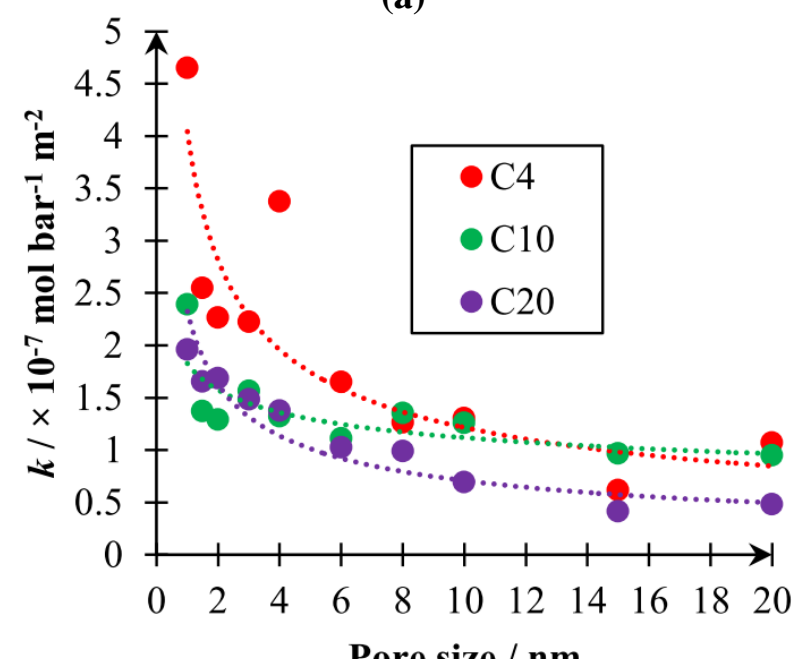

Pore size / nm

(c)

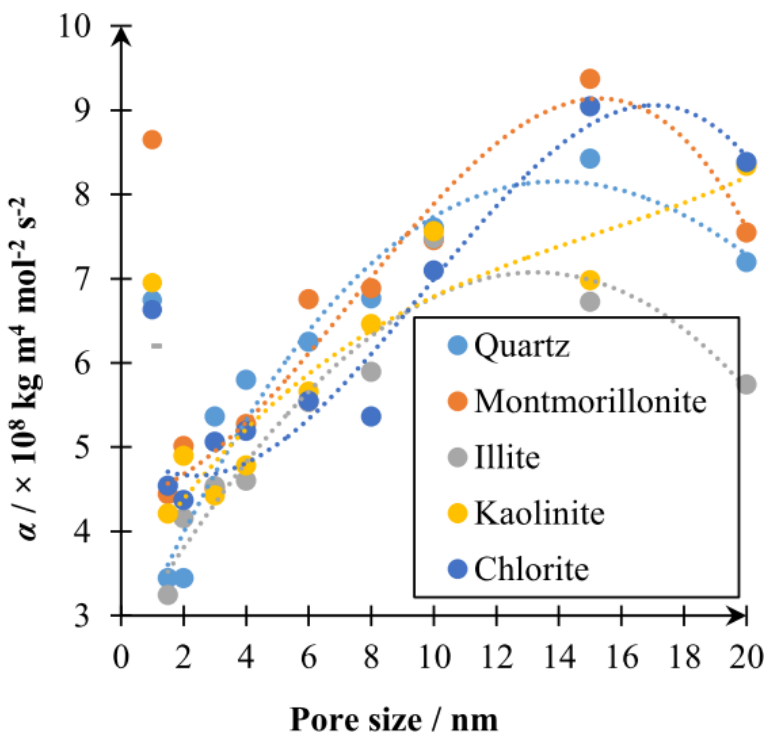

(e)

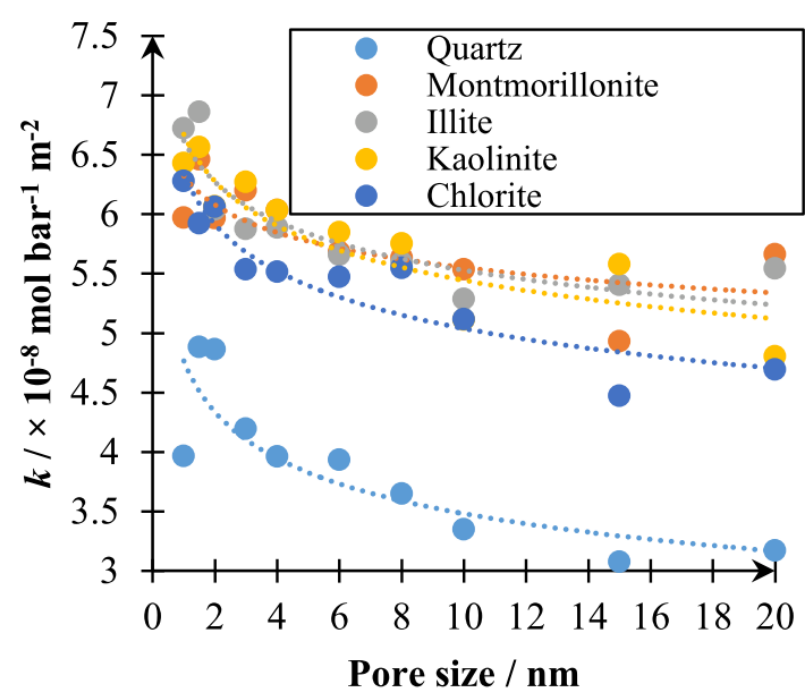

(b)

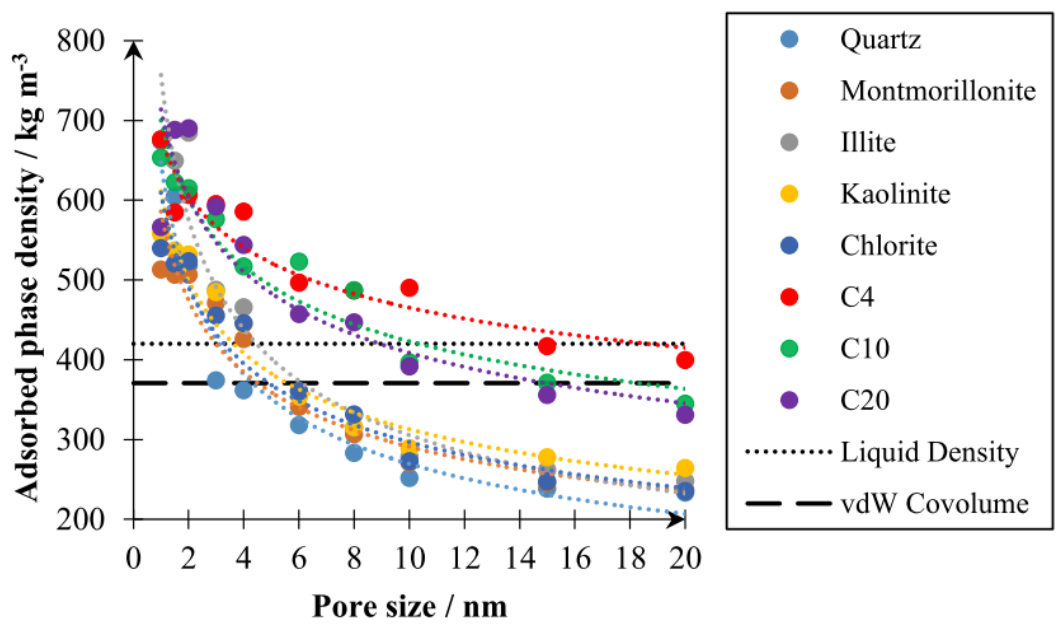

(d)

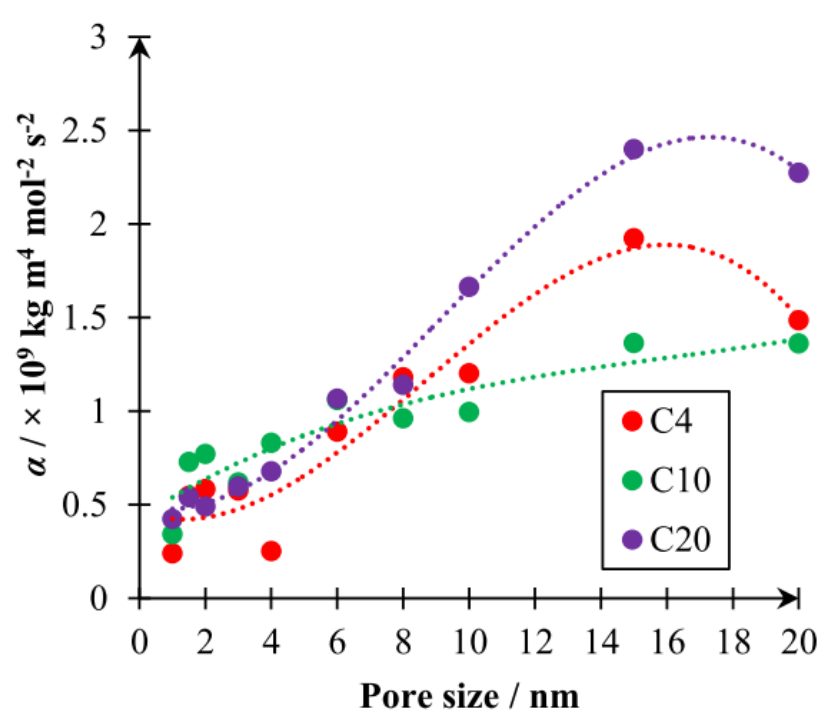

(f)

Figure 5. (a) Variation of $\beta$ with pore sizes for nano-capillaries regressed using PR EoS, (b) variation of $k$ with pore sizes for mineral capillaries, (c) variation of $k$ with pore sizes for carbon-based capillaries, (d) variation of adsorbed phase density with pore sizes for nanocapillaries, (e) variation of $\alpha$ with pore size for mineral-based capillaries, and (f) variation of $\alpha$ with pore size for carbon-based capillaries. 


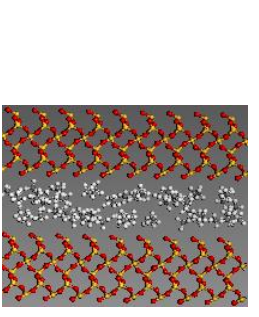

Quartz

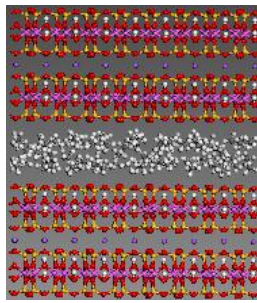

Montmorillonite

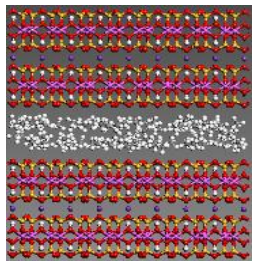

Illite

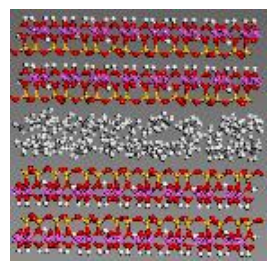

Kaolinite

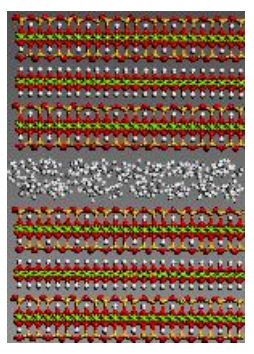

Chlorite

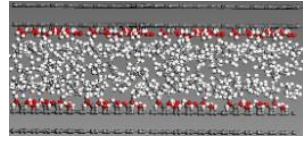

$\mathrm{C} 4$

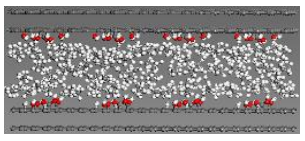

$\mathrm{C} 10$

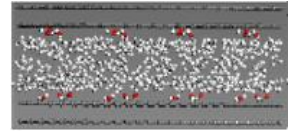

$\mathrm{C} 20$

Figure 6. Molecular arrangement of methane molecules in $1 \mathrm{~nm}$ pores at $20 \mathrm{MPa}$ and $333 \mathrm{~K}^{45}$. $\mathrm{O}$ is an oxygen atom, $\mathcal{Q}$ is a carbon atom, $\mathcal{Q}$ is a hydrogen atom, $\mathcal{O}$ is a silicon atom, $\mathcal{Q}$ is an aluminium atom, $\mathcal{Q}$ is a magnesium atom, $\mathcal{O}$ is a sodium atom, and $\mathcal{O}$ is a potassium atom ${ }^{45}$.

\subsection{2. $k$ parameter}

Based on the regressed parameters of parameter $k$, it is found that the value of $k$ decreases exponentially within increasing pore size, as shown in Figure 5(b) and Figure 5(c), where the graph can be best fit using a power-law graph. Since $k$ is analogous to the Henry's Constant of Langmuir model, the decrease in the value of $k$ essentially means the adsorption interaction at infinitesimally small pressure decreases with increasing pore size. The higher the value of $k$, the stronger is the attractive interaction between the adsorbent and the adsorbate. As mentioned in Section 4.2.1, the superimposition effect within the pore decreases with increasing pore size. This causes a reduction in the interactive forces and therefore, reduces the absolute adsorption on the walls. Similar to the conditions found for the $\beta$ parameter, $k$ has an anomalous value for mineral nano-capillaries at pore size of $1 \mathrm{~nm}$ as the $k$ value does not follow the general trend when the pore size decreases from 1.5 $\mathrm{nm}$ to $1 \mathrm{~nm}$ for minerals-based capillaries. Based on the general trend, the value should increase but it shows the opposite. There is a high possibly that this is due to the limited pore volume within the capillaries that causes adsorption to be relatively weaker at the small pore size.

In contrary to the $\beta$ value of both carbon-based and mineral capillaries where at the same pore size, both types of capillaries show almost equivalent values, such a phenomenon is not observed in $k$ values. The $k$ value for carbon capillaries is about an order higher than mineral capillaries. This indicates that the carbon-based capillaries have higher adsorption strength than mineral capillaries. 
Besides, it is important to note that the decrease of $k$ value with pore size is less significant in mineral capillaries as the percentage decrease ranges from 22.9 to $37 \%$ only. However, in carbon-based capillaries, the value is between 60.9 and $86.7 \%$. As carbon-based capillaries are stronger adsorbents, the superimposition effect created when the two pore walls are at close proximity creates a stronger adsorption field in carbon-based capillaries.

The value of $k$ is calculated to be $5.13 \times 10^{-10} \mathrm{~mol} \mathrm{bar}^{-1} \mathrm{~m}^{-2}$ for pure carbon-based capillaries from the Ono-Kondo Predictive Model. This value is 2 orders of magnitude smaller than mineral capillaries and 3 orders for carbon capillaries. It is also independent to the pore size. Therefore, this concludes that predictive equations or specific terms used to calculate $k$ require refinements in order for application of the predictive model on nanopores. Since $k$ defines the adsorption behaviour at infinitesimally small pressures, the large difference between that predicted and regressed values is attributed to the adsorption behaviour at low pressures. In bulk adsorbents, molecules are adsorbed on the bulk outer surface of the adsorbent as well as the pore walls of the macropores and mesopores. Macropores and mesopores have considerably less surface area per volume ratio for adsorption. The presence of such large pores reduces the ability of the bulk adsorbent and reduces the value of $k$. Since the value of $k$ at all pore sizes deviates far from the bulk scale predictive model, it is essential to classify the terms in the predictive model that requires refinements or modifications such the model can be extended to nanopores.

The Ono-Kondo Lattice Theory model calculates the value of $k$ based on the value of $\beta$, maximum adsorbate phase density, $\rho_{m c}$, and fluid-solid interaction energy, $\varepsilon_{f s}$. In Section 4.2.1, it was shown that the value of $\beta$ varies with pore size, especially at pore size below $15 \mathrm{~nm}$. However, the value approaches that of the predictive model at pore sizes more than $15 \mathrm{~nm}$. Based on the Ono-Kondo model, $\rho_{m c}$ can also be predicted from either the van der Waals co-volume or assumed to be the liquid density of the component at the normal boiling point ${ }^{21}$. Therefore, it is important to ensure the applicability of such assumption when applied to nanopores. The determination of the value of $\rho_{m c}$ is carried out based on the slope method on the linear line of the Gibbs' excess adsorption isotherm developed by Zhang et al. ${ }^{14}$. Results from the analysis are presented in Figure 5(d).

The analysis shows a trend similar to the $k$ value for all capillaries, where the adsorbed phase density decreases exponentially with increasing pore size. The adsorbate phase has a higher density at small pores due to the superimposition effect imposed by the opposing wall. As the effect decreases with increasing pore size, the adsorbed phase density decreases. Generally, the adsorbate in carbon capillaries has a relatively higher density due to the stronger attractive forces by the pore walls. An important thing to note is that at extremely small pore sizes, smaller than $2 \mathrm{~nm}$, the adsorbed phase density for all capillaries are higher than both that calculated from vdW co-volume or the liquid density at normal boiling point. This means the superimposition effect has significantly enhanced the 
adsorbate density, higher than that of a single wall-adsorbate interaction. Since carbon-based capillaries create a stronger force field, this allows the effect to be extended to about $10 \mathrm{~nm}$.

In addition, it is important to note that in carbon capillaries, the adsorbed phase density approaches that of liquid density and vdW co-volume with increasing pore size. For mineral capillaries, the adsorbed phase density drops below both predicted values for pore sizes more than $6 \mathrm{~nm}$. Quartz has the lowest adsorbed phase density, followed by the remaining four mineral-based capillaries and the carbon-based capillaries. This is also consistent with previous research carried out that have proved quartz is the least adsorbing in the coal bed, followed by minerals and the most adsorbing is carbon ${ }^{10}$. It is difficult to identify which mineral has a higher adsorption strength as the line of best fit overlaps with one another at certain pore sizes. As illustrated in Figure 5(d), the adsorption strength varies with pore size and in a bulk scale, the adsorption strength will be directly related to the pore size distribution of each mineral within the coal, which varies quite significantly depending on the source of the coal. In a bulk scale experimental investigation in these minerals, the methane adsorption strength is found to be highest in montmorillonite, followed by kaolinite, chlorite and illite ${ }^{55,56,57}$.

\subsection{3. $\alpha$ parameter}

In bulk scale adsorption system, the $\alpha$ parameter is associated to the intermolecular fluid-fluid interactions within the adsorbed phase. A more accurate representation of the value of $\alpha$ requires a correction using the adsorbate-adsorbent interactions and based on the predictive model, the value is also independent to that of the pore sizes. Regressed $\alpha$ values for the different capillaries are presented in Figure 5(e) and Figure 5(f). It can be observed that the value of $\alpha$ generally increases with pore size for all capillaries before decreasing at $15 \mathrm{~nm}$. The magnitude of $\alpha$ for carbon-based capillaries, which are more adsorbing, is also an order higher than the mineral capillaries. Generally, the values of $\alpha$ increases with pore size for all capillaries. However, there are anomalous values at 1 $\mathrm{nm}$ for the five mineral capillaries. The reason for this phenomenon is similar to that of $\beta$. Due to the stronger repulsive interactions between the mineral atoms and the fluid molecules, this results in the adsorbing molecules being adsorbed at a distance further away from the wall, leading to a limited pore volume. As carbon capillaries have stronger attractive forces, this behaviour is not observed as the adsorbed phase forms closer to the pore walls, as observed from molecular simulations ${ }^{45}$.

Based on the predictive model, the values of $\alpha$ for adsorbing systems are generally negative due to the stronger fluid-solid attractive forces that allow adsorption to take place. The more negative the value of $\alpha$, the stronger the fluid-solid interactions and the adsorbent system. However, the regressed $\alpha$ parameters are positive for all sizes and material of capillaries being investigated. Based on the predictive model, $\alpha$ is $-7.68 \times 10^{9} \mathrm{~kg} \mathrm{~m}^{4} \mathrm{~mol}^{-2} \mathrm{~s}^{-2}$ for a bulk scale pure, single-surface graphite system. Therefore, although the magnitude of the values obtained from the regressed and predictive method are comparable with each other, refinements to the predictive equations will be required to 
ensure an accurate representation of the adsorption in nanopores. Detailed investigation into the derivation of parameter $\alpha$ calculation equations from the lattice theory model reveals that the authors utilise a non-rigorous approximation method to take into account the adsorbent-adsorbate interaction energy. This is suitable for bulk scale systems where the interaction energy is only between a singlesurface adsorbent and the fluid. However, in nanopores, other factors such as the force caused by the opposing wall and the limited pore volume have to be taken into account in the determination of $\alpha$.

\subsection{Thermodynamic factor for pure component adsorption isotherms}

The thermodynamic factor, $\Gamma$, for pure component adsorption isotherm can be determined from an analytical differentiation of the 2-D EoS adsorption isotherms. Previous investigations have utilised the Langmuir model to fit adsorption isotherms in nanopores and calculate the thermodynamic factor $^{15,13}$. However, as mentioned previously, adsorption in nanopores do not obey the fundamental assumptions underlying the Langmuir model. This includes the fact that adsorption in nanopores is multilayer and the adsorption sites do not have equivalent enthalpy of adsorption ${ }^{17}$. In fact, at high pressures, the adsorbent gradually shifts from high energy adsorption sites to lower energy ones in order to increase the adsorption capacity ${ }^{45}$.

\subsubsection{Comparison of 2-D EoS with Langmuir model}

The values for Langmuir model-based thermodynamic factor are determined by previous research using total loading values instead of absolute adsorption ${ }^{13}$. Based on the results presented in Figure 7, it can be noted that apart from methane in $4 \mathrm{~nm}$ pore, thermodynamic factor of other EoS's deviate significantly from that determined from Langmuir model. However, all EoS's produce identical values for thermodynamic factor. It can be concluded that the choice of model used to quantify the adsorption isotherm plays an important role in determining the thermodynamic factor. As previously mentioned, assumptions involved in the application of Langmuir model are not observed in small nanopores adsorption. Thus, use of such a model will cause a strong deviation from the actual behaviour. On the other hand, the 2-D EoS is only based on the chemical equilibrium between the adsorbate phase and bulk phase, a critical phenomenon that must be observed in all adsorption systems. Therefore, the use of 2-D EoS should be a more appropriate candidate in determining the thermodynamic factor. 

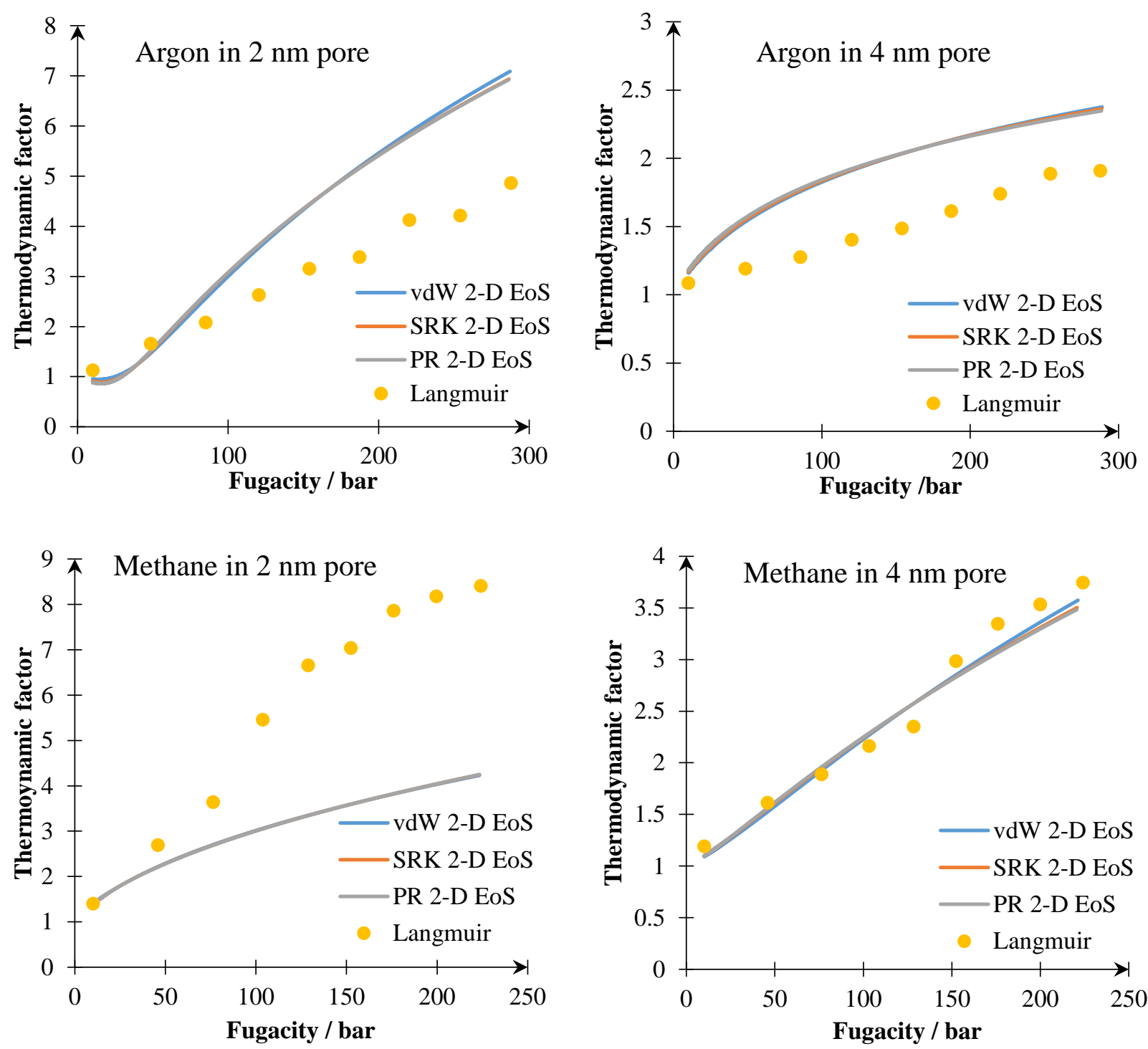

Figure 7. Thermodynamic factor for 2-D EoS adsorption isotherms in comparison with Langmuir model.

\subsubsection{Influence of pore size on thermodynamic factor}

Here, the thermodynamic factor variation with pore sizes for mineral and carbon capillaries are investigated. All EoS's being analysed in this section produced the same trend and values of thermodynamic factor for the same pore size and type of capillary being investigated similar to that shown in Section 4.3.1. Therefore, only thermodynamic factor calculated from PR EoS are presented in this section to ensure consistency with the data displayed in Section 4.2. Based on previous investigations carried out on diffusion mechanisms in nanopores, the confinement effects have a strong influence on the type of diffusion occurring in the pore. The transport rates and contributions of the four flow dominant flow regimes (slip flow, Darcy flow, transition flow and Knudsen flow) depend heavily on the adsorption effects, which is a function of pore size and pressure ${ }^{58,59}$. The use of 
thermodynamic factor will allow the correction of Fick's diffusivity directly to the self-diffusion coefficient of the molecule in the capillary, taking into account all diffusive mechanisms ${ }^{43}$.

The analysis is carried out for all 5 mineral capillaries and 3 carbon capillaries similar to that presented in Section 4.2. Based on the results presented in Figure 8, it can be seen that as fugacity of the system increases, the thermodynamic factors for all capillaries increase. At higher fugacities, the absolute adsorption is higher and this result in a higher thermodynamic factor, meaning that the actual diffusion is much lower compared to the Fick's diffusivity at higher reservoir pressures. The degree of increase in the thermodynamic factor for montmorillonite capillary in Figure 8(a) with pore size is also lower than that of carbon capillary in Figure 8(b). This is because mineral capillaries are less adsorbing, as explained in Section 4.2.2, where $k$ values stay relatively constant with pore size. Therefore, it is concluded that thermodynamic factors for these capillaries are not significantly affected by pore sizes.

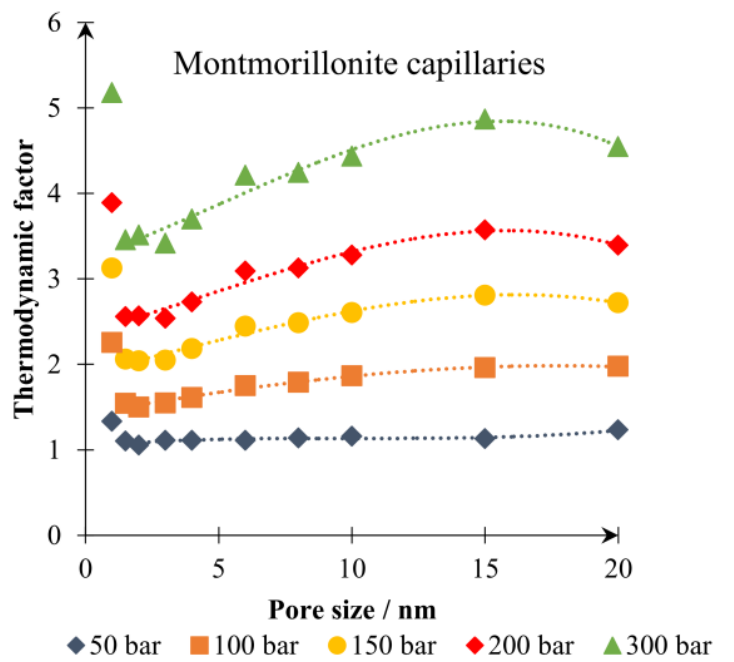

(a)

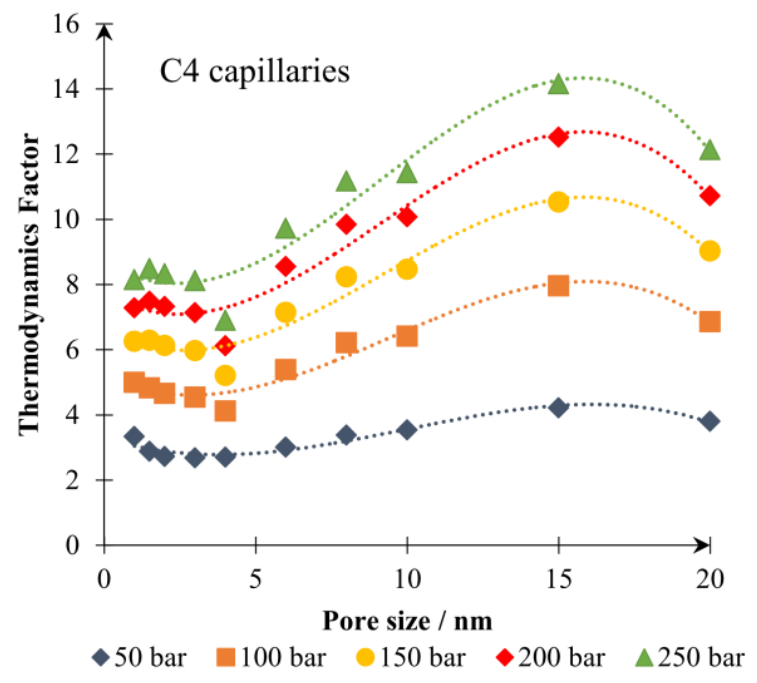

(b)

Figure 8. Thermodynamic factor variation with pore size for (a) Montmorillonite capillaries and (b) C4 capillaries.

It can also be noted that for all pore sizes smaller than $4 \mathrm{~nm}$, the degree of variation in the thermodynamic factor for carbon capillaries is negligible, which is consistent with result from molecular simulations. At such small pore systems, Knudsen diffusion dominates the flow and wall adsorption effects have less impact on the diffusive flow ${ }^{60}$. The minimum value in the thermodynamic factor at $4 \mathrm{~nm}$ may also indicate the transition of the transport regime from Knudsen diffusion to slip flow, a behaviour that has been observed in molecular simulations. In the slip regime, walls adsorption effects have a strong influence on the diffusive flow. This may explain why above $4 \mathrm{~nm}$, the thermodynamic factor for carbon capillaries increase more significantly with pore size ${ }^{61}$. 


\subsection{Binary mixture adsorption results}

In this section, the adsorption isotherms for a binary $\mathrm{CH}_{4}-\mathrm{CO}_{2}$ mixture is presented and discussed. The 2-D EoS pure component adsorption isotherm parameters for methane and carbon dioxide for a 2 $\mathrm{nm}$ nanopore are determined from Kazemi and Takbiri-Borujeni ${ }^{44}$ and the regressed parameters are presented in Table 4 of Section 4.1.

\subsubsection{Equation of State on the prediction of binary adsorption behaviour}

The first simulation presented is the comparison of the equation of state when the total pressure of the system is increased at equivalent molar fraction of $\mathrm{CH}_{4}$ and $\mathrm{CO}_{2}$ of 0.5 respectively. This allows the comparison of the 2-D EoS result obtained with the Langmuir model as well as the performance of different equations of state in quantifying modelling binary adsorption isotherms. Binary interaction parameter, $k_{12}$, is assumed to be equivalent of that of the cubic EoS system, which is $0.0919^{48,49}$. Based on previous investigations carried out on bulk scale adsorption isotherms, the interaction parameter does not have a significant effect on the prediction of adsorption behaviour, especially with non-polar adsorbent molecules such as this system ${ }^{19,32}$. Both carbon dioxide and methane are nonpolar molecules and the binary interaction is by weak van der Waals forces only. It should also be noted that both Redlich-Kwong (RK) and Soave-Redlich-Kwong (SRK) EoS predict equivalent values for both pure component and binary component. Therefore, only SRK EoS data are presented.

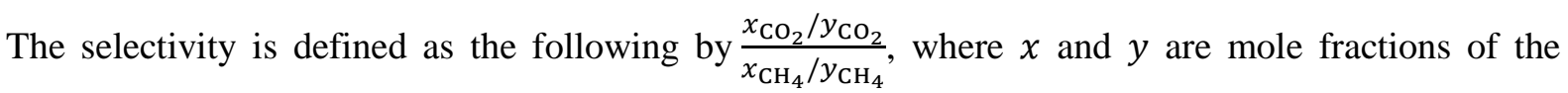
component in the adsorbed phase and bulk phase respectively.

Results of the simulation carried out are presented in Figure 9, where it can be noted as the total pressure increases, both vdW EoS and Langmuir model produces completely different results from SRK and PR EoS respectively. Both vdW EoS and Langmuir models predict that if the total pressure of the system is increased, both the moles of $\mathrm{CH}_{4}$ and $\mathrm{CO}_{2}$ adsorbed increase gradually. The selectivity of $\mathrm{CO}_{2}$ over $\mathrm{CH}_{4}$ stays reasonably constant throughout the pressure range being investigated. The phenomenon observed in Langmuir and vdW EoS models are similar to that observed for bulk scale carbon or coal adsorption systems, where the selectivity stays reasonably constant or decreases slightly with increasing bulk pressure at equivalent mole fractions ${ }^{62}$. On the other hand, SRK and PR EoSs predict a two-step adsorption mechanism with similar adsorption isotherms. As the total pressure of the system increases, both amounts of $\mathrm{CH}_{4}$ and $\mathrm{CO}_{2}$ in the adsorbate increases initially until the pressure reaches $60 \mathrm{~atm}$, then the amount of methane in the adsorbate decreases while carbon dioxide increases drastically as the system pressure further increases. Both graphs start to plateau off at $200 \mathrm{~atm}$. As a result, the selectivity of $\mathrm{CO}_{2}$ over $\mathrm{CH}_{4}$ in the system experiences a significant increase at pressures over $60 \mathrm{~atm}$. The adsorption behaviours and 
two-step mechanism demonstrated by both SRK and PR are supported by another molecular simulation research carried out on carbon nano-capillaries at sizes of 0.66 to $1.61 \mathrm{~nm}^{63}$.
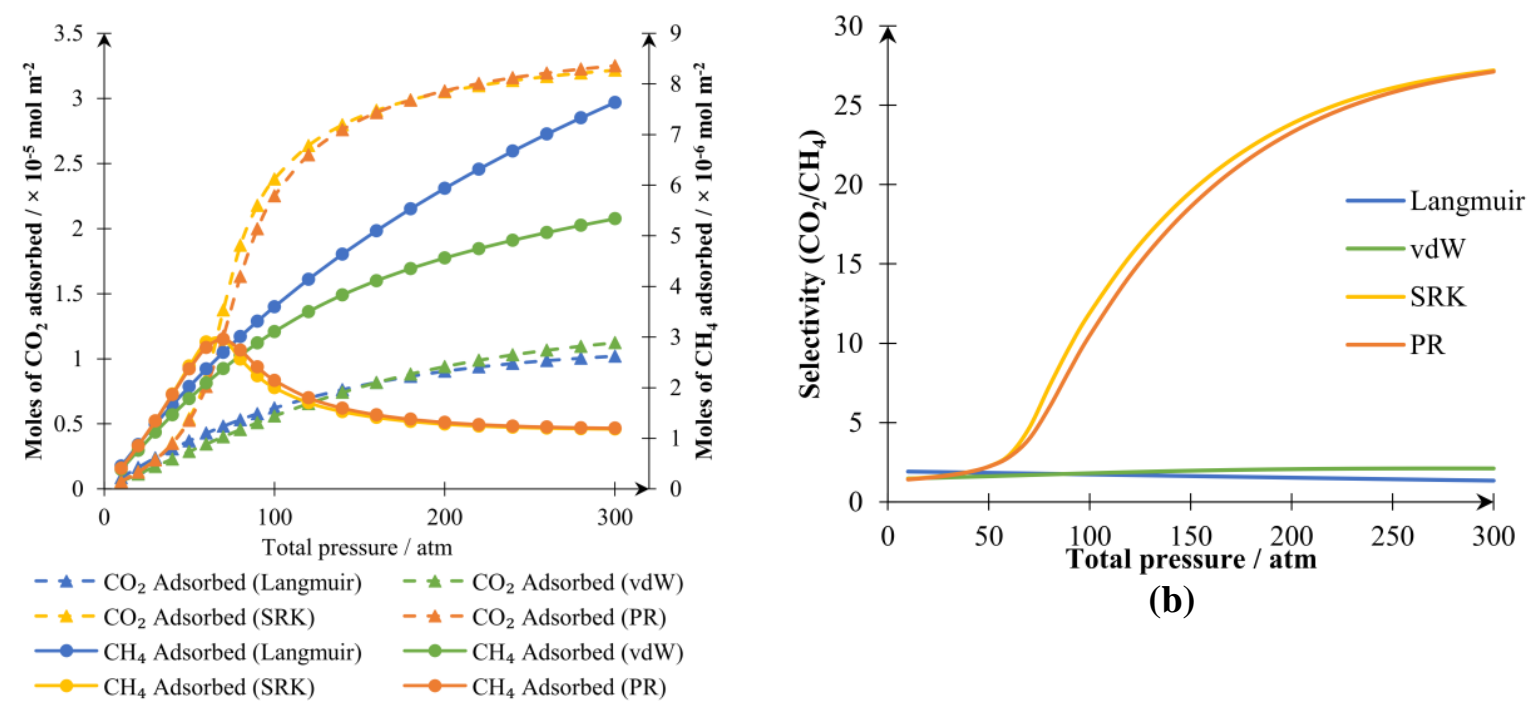

(b)

(a)

Figure 9. (a) Absolute adsorptions of $\mathrm{CO}_{2}$ and $\mathrm{CH}_{4}$ at different pressures, (b) selectivity of adsorption of $\mathrm{CO}_{2}$ over $\mathrm{CH}_{4}$ at varying pressures.

\subsubsection{Displacement of methane by carbon dioxide}

Although both Langmuir and vdW models are inappropriate in predicting pure component adsorption isotherms due to the inability to take into account multilayer adsorption and high pressure systems respectively, both of these models show different results in binary systems to that of SRK and PR EoS. Therefore, in this section, an enhanced coal bed methane (ECBM) recovery process using $\mathrm{CO}_{2}$ technique is simulated by increasing the pressure of $\mathrm{CO}_{2}$ in the $2 \mathrm{~nm}$ capillary while keeping the pressure of $\mathrm{CH}_{4}$ constant in the carbon capillary. Based on previous investigations carried out through molecular simulations, the displacement of methane from coal bed or shale by injecting carbon dioxide is aided by the presence of nanopores via a two-step enhancement and displacement mechanism ${ }^{63}$. Therefore, by comparing the results obtained from SRK and PR EoSs models with that of Langmuir and vdW EoS models as well as the molecular simulations, the applicability of the latter two models on binary adsorption systems can be determined. 


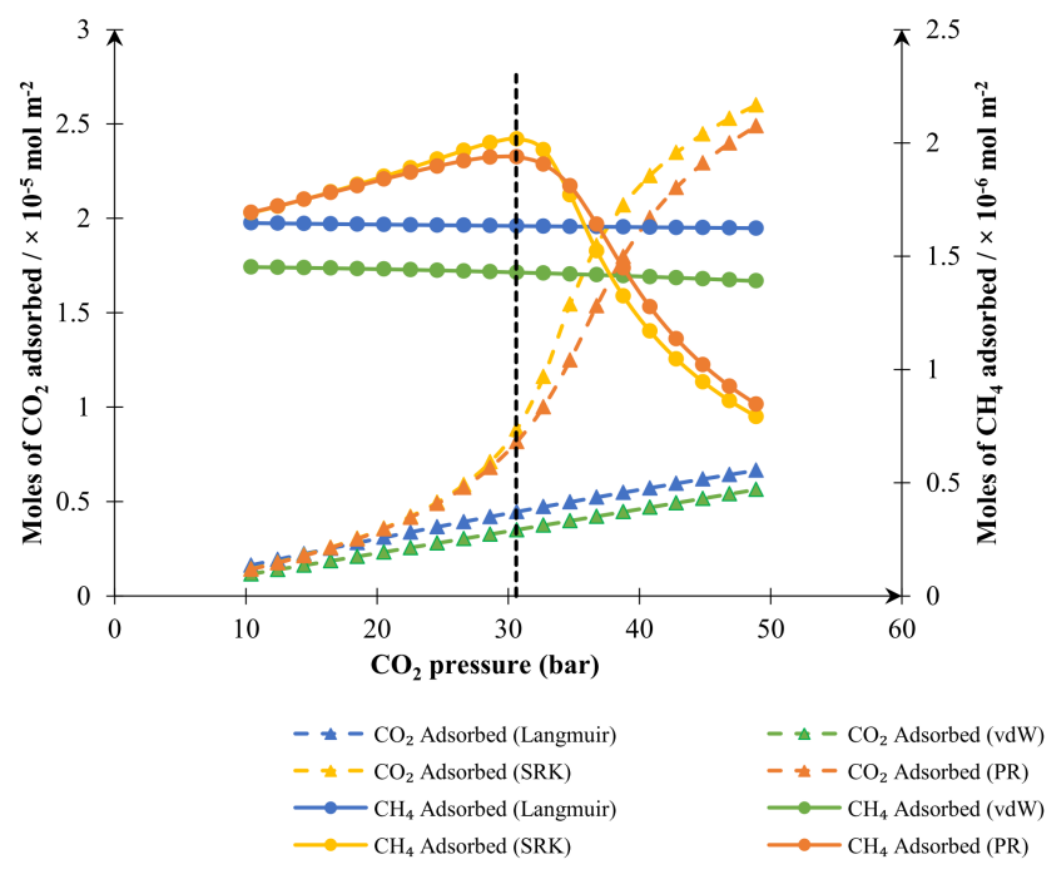

Figure 10. Absolute adsorption of $\mathrm{CO}_{2}$ and $\mathrm{CH}_{4}$ at different $\mathrm{CO}_{2}$ pressures at constant $\mathrm{CH}_{4}$ pressures of 20 bar.

From Figure 10, it can be observed that the adsorption behaviours are similar to that of Figure 9. For the Langmuir and vdW EoS models, when the $\mathrm{CO}_{2}$ pressure increases in the capillary at constant $\mathrm{CH}_{4}$ pressure, the moles of $\mathrm{CH}_{4}$ adsorbed generally decreases whiles $\mathrm{CO}_{2}$ adsorbed increases. This means that $\mathrm{CH}_{4}$ at the adsorption sites in the capillary are just generally replaced by $\mathrm{CO}_{2}$. The percentage decrease in $\mathrm{CH}_{4}$ adsorbed predicted by vdW and Langmuir model are $1.38 \%$ and $4.25 \%$, respectively. Both SRK and PR EoS's are able to predict the two-step enhancement-displacement mechanism. As the pressure of $\mathrm{CO}_{2}$ increases from 10 to $30 \mathrm{bar}$, the amount of $\mathrm{CH}_{4}$ increases although there is no increase in the amount of $\mathrm{CH}_{4}$ within the bulk fluid. This is due to the external force field created by the adsorbed $\mathrm{CO}_{2}$ that induces further enhancement of adsorbent-adsorbate interactions with the bulk $\mathrm{CH}_{4}$ molecules. Beyond that point, additional $\mathrm{CO}_{2}$ injected into the capillary cause displacement of $\mathrm{CH}_{4}$ from the adsorbed layer, which decreases the amount of $\mathrm{CH}_{4}$ adsorbed significantly. Thus, creating a two-step enhancement-displacement mechanism as observed from molecular simulations ${ }^{63}$. The results have further demonstrated the inapplicability of Langmuir and vdW models in predicting adsorption in nanopores. Although the pure component adsorption isotherms can be fitted by the parameters of these two models, the fundamental assumptions underlying these two models do not reflect the actual adsorption behaviour occurring in the pore, causing a deviation from the actual adsorption behaviour. Soave-Redlich-Kwong (SRK) and Peng-Robinson (PR) EoS are able to take into account the enhanced solid-fluid interactions within the nanopores and lead to an accurate prediction of the binary adsorption behaviour due to their ability in modelling high pressure fluids. 
Therefore, both SRK and PR EoS's should be utilised in future adsorption isotherm models for accurate adsorption representations.

\subsection{Thermodynamic factor for binary mixture isotherms}

Thermodynamic factors for the binary $\mathrm{CH}_{4}-\mathrm{CO}_{2}$ mixture are determined by numerical differentiation. Due to the similarity in the trend of SRK and PR EoS's, only the thermodynamic factor determined from the PR EoS is presented in this section. It should be noted that the thermodynamic factor, $\Gamma$ allows the correction of Fick's diffusivity, $D_{t}$, to the actual diffusivity occurring in the nanopore, $D_{c}$, by equation $D_{t}=\Gamma \times D_{c}$. Therefore, if $\Gamma$ drops below 1 , it means the actual diffusivity is higher than that of Fick's diffusivity. As illustrated in Figure 11, it is seen that for the pure component, the thermodynamic factor stays above 1 and increases linearly with fugacity of $\mathrm{CH}_{4}$. This is due to the increased amount of $\mathrm{CH}_{4}$ adsorbed as the fugacity increases. Thus, this reduces the diffusion rate and diffusivity of $\mathrm{CH}_{4}$ in the nanopore.

Presence of $\mathrm{CO}_{2}$ in the binary system at constant fugacity below 25 bar has no significant effect on the thermodynamic factor. The thermodynamic factor still approaches that of the pure component isotherm. By relating this diffusion effect to the adsorption isotherm behaviour presented in Section 4.4.2, the enhancement of $\mathrm{CH}_{4}$ occurs at pressure below 30 bar and as the pressure increases to above 30 bar, the displacement behaviour occurs. Therefore, as the fugacity of the $\mathrm{CO}_{2}$ increases above 30 bar, the thermodynamic factor at low fugacity starts to decrease gradually to below 1 , reaching a minimum value before increasing linearly to more than 1 . This means that the presence of $\mathrm{CO}_{2}$ has caused $\mathrm{CH}_{4}$ to be displaced from the adsorbed layer, increasing its diffusion coefficient. An important note to add is that as the fugacity of $\mathrm{CO}_{2}$ increases, the point of $\mathrm{CH}_{4}$ fugacity at which minimum thermodynamic factor is observed is also increased. This means that as $\mathrm{CH}_{4}$ pressure in the capillary increases, the pressure of $\mathrm{CO}_{2}$ at which the maximum diffusion rate of $\mathrm{CH}_{4}$ occurs is higher. Overall, it can be concluded that both the displacement and diffusion of methane are facilitated by the presence of $\mathrm{CO}_{2}$. 


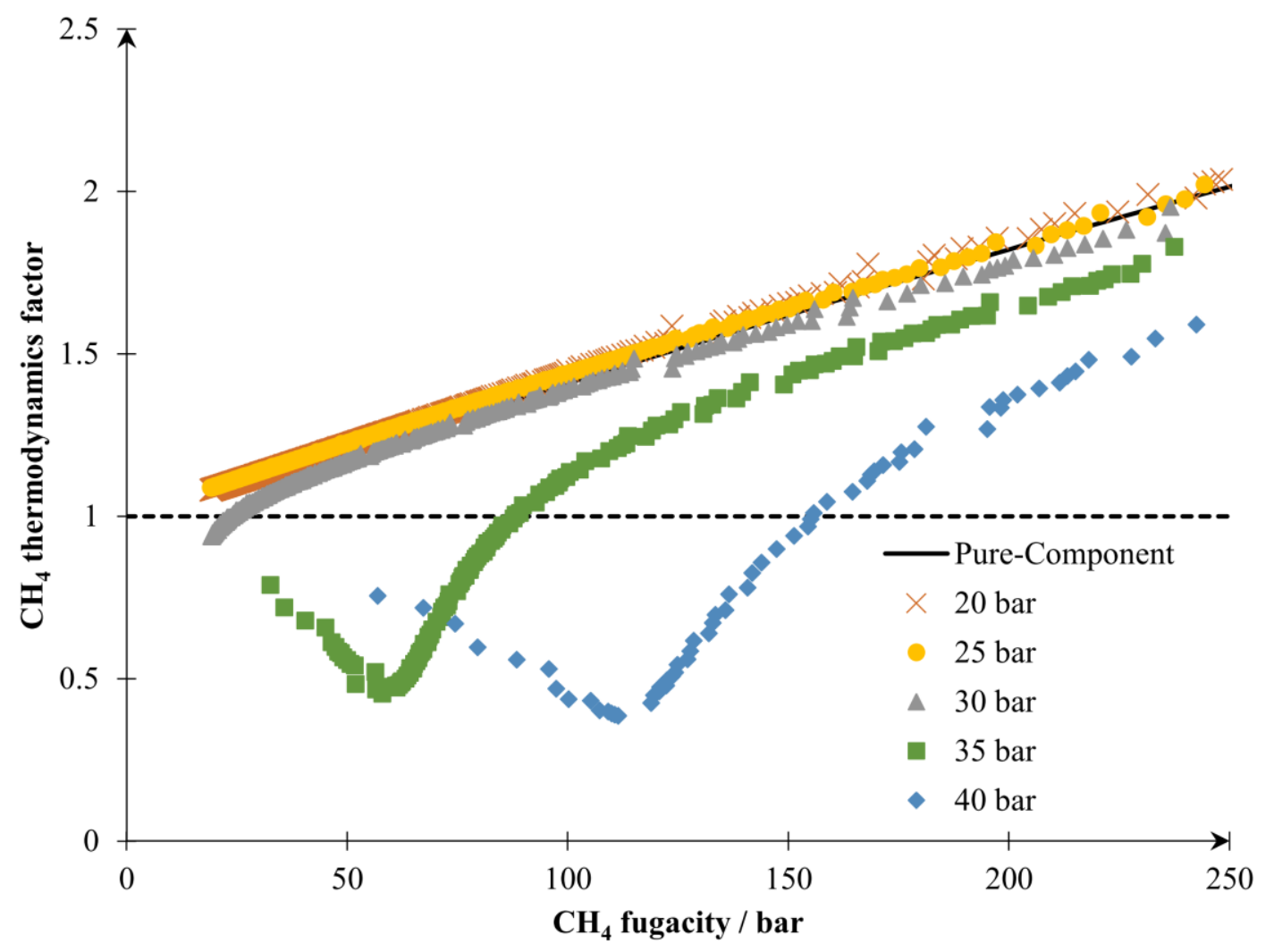

Figure 11. $\mathrm{CH}_{4}$ thermodynamic factor at varying $\mathrm{CH}_{4}$ pressures and constant but different $\mathrm{CO}_{2}$ partial pressures.

\section{5 - Conclusions and future works}

In this work, the thermodynamics-based Two-Dimensional Equation of State (2-D EoS) adsorption isotherm has shown a good fit of data for all adsorbate and adsorbents being investigated in this case. This meant that such a methodology can be applied to adsorption isotherms in all nanopore sizes without considering the adsorption behaviour and layers of adsorption taking place within the pores itself, reducing assumptions required in modelling the adsorption isotherms. Soave-Redlich-Kwong and Peng-Robinson were found to be the best EoS used to fit the adsorption isotherms. The variation of adsorption isotherm parameters with pore sizes is also found to be consistent with the adsorption behaviour within the system. With the application of pure component adsorption isotherm parameters, the 2-D EoS approach was shown to simulate the two-step enhancement-displacement mechanism of methane by carbon dioxide in carbon nanopores, a behaviour that was observed from molecular simulations. Both pure and binary component diffusion thermodynamics correction factor can also be calculated accurately from the isotherms. Therefore, it is concluded that the 2-D EoS allows the calculation of self-diffusion coefficient directly from Fick's diffusivity, providing an alternative approach to determine diffusivity in nanopores in the future. 
From the results of this research, it is suggested that quantitative absolute errors in the adsorption isotherms determined from molecular simulations should be included as part of the published research in the future. This can be used in combination with the average absolute deviation obtained from regression for a more accurate calculation and trend determination of the 2-D EoS adsorption isotherm parameters. Adsorption isotherms obtained from molecular simulations should also be expressed in terms of absolute adsorption rather than pore density or total loadings, which allow a direct application of the 2-D EoS model on the determination of adsorption isotherm. In the near future, pore size dependent regression parameters for pure carbon dioxide adsorption isotherms can be determined and used in combination with that of methane determined from this research. This will allow for the simulation of adsorption behaviour in the methane-carbon dioxide binary mixture at other pore sizes. This will ensure that a direct comparison of the results with that obtained from molecular simulations, proving the applicability of 2-D EoS in the prediction of binary mixture adsorption isotherm.

On the other hand, superimposition effect and limited pore space within the pores have resulted in a strong deviation of adsorption effect from bulk scale Ono-Kondo Lattice Theory predictive model, limiting its application on nanopore scale. In the future, refinements to the model have to be carried out to take into account all pore adsorption effects. This will include the adsorptive and repulsive forces acted upon by the layers of walls as well as the limited pore space factor. Temperature effect equations on the adsorption isotherm parameters have to be improved to remove the assumption of constant thermal expansion coefficient, allowing the extension of the model application to high pressure high temperature (HPHT) conditions. This will allow such combined Ono-Kondo and 2-D EoS model not only to be constrained to upstream petroleum sector such as capacity and recovery rate estimation of petroleum reservoirs but as well as downstream unit operations such as HPHT catalytic reactors and adsorption columns.

Overall, this research should have provided a new and clear methodology to quantify and describe adsorption behaviour in nanopores. It has also introduced an alternative method to calculate diffusion in nanopores. It is hoped that in the future, adsorption isotherms and diffusion coefficients in any pore size can be determined accurately in a much shorter computational time by applying this thermodynamics-based approach. It may even be possible that in the future, overall adsorption and diffusion rate coefficients in a bulk scale can be determined accurately from pore size distributions without the need of classical adsorption experiments.

\section{Acknowledgment}

MB's contribution to this work was mad possible thanks to the American Chemical Society Petroleum Research Fund \# 59217-ND9. MB thanks this organization. 


\section{References}

(1) Llewellyn, L. Shale Gas and Coal-Bed Methane (unconventional Gas). A publication of National Assembly of Wales 2012.

(2) Suárez, A. A. The Expansion of Unconventional Production of Natural Gas (tight Gas, Gas Shale and Coal Bed Methane). In Advances in Natural Gas Technology; IntechOpen, 2012.

(3) Godec, M. L.; Jonsson, H.; Basava-Reddi, L. Potential Global Implications of Gas Production from Shales and Coal for Geological CO2 Storage. Energy Procedia 2013, $37,6656-6666$.

(4) McGlade, C.; Speirs, J.; Sorrell, S. Methods of Estimating Shale Gas ResourcesComparison, Evaluation and Implications. Energy 2013, 59, 116-125.

(5) Delbeke, J.; Vis, P. EU Climate Policy Explained; Routledge, 2015.

(6) Olivier, J. G. I.; Peters, J. A. H. W.; Janssens-Maenhout, G. Trends in Global CO2 Emissions 2012 Report. 2012.

(7) Mazzotti, M.; Pini, R.; Storti, G. Enhanced Coalbed Methane Recovery. The Journal of Supercritical Fluids 2009, 47, 619-627.

(8) Godec, M. L.; Kuuskraa, V. A.; Dipietro, P. Opportunities for Using Anthropogenic $\mathrm{CO} 2$ for Enhanced Oil Recovery and CO2 Storage. Energy \& Fuels 2013, 27, 41834189.

(9) Guo, C.; Wei, M.; Liu, H. Modeling of Gas Production from Shale Reservoirs Considering Multiple Transport Mechanisms. PloS one 2015, 10, e0143649.

(10) Mosher, K.; He, J.; Liu, Y.; Rupp, E.; Wilcox, J. Molecular Simulation of Methane Adsorption in Micro-and Mesoporous Carbons with Applications to Coal and Gas Shale Systems. International Journal of Coal Geology 2013, 109, 36-44.

(11) Guo, X.; Li, Y.; Liu, R.; Wang, Q. Characteristics and Controlling Factors of Micropore Structures of the Longmaxi Shale in the Jiaoshiba Area, Sichuan Basin. Natural Gas Industry B 2014, 1, 165-171.

(12) Curtis, J. B. Fractured Shale-Gas Systems. AAPG bulletin 2002, 86, 1921-1938.

(13) Kazemi, M.; Takbiri-Borujeni, A. Modeling and Simulation of Gas Transport in Carbon-Based Organic Nano-Capillaries. Fuel 2017, 206, 724-737.

(14) Zhang, J.; Clennell, M. B.; Liu, K.; Pervukhina, M.; Chen, G.; Dewhurst, D. N. Methane and Carbon Dioxide Adsorption on Illite. Energy $\backslash \&$ Fuels 2016, 30, 1064310652. 
(15) Kazemi, M.; Takbiri-Borujeni, A. Flow of Gases in Organic Nanoscale Channels: A Boundary-Driven Molecular Simulation Study. Energy $\backslash \&$ Fuels 2016, 30, 8156-8163.

(16) Shahbeig, H.; Bagheri, N.; Ghorbanian, S. A.; Hallajisani, A.; Poorkarimi, S. A New Adsorption Isotherm Model of Aqueous Solutions on Granular Activated Carbon. World Journal of Modelling and Simulation 2013, 9, 243-254.

(17) Torres-Knoop, A.; Poursaeidesfahani, A.; Vlugt, T. J. H.; Dubbeldam, D. Behavior of the Enthalpy of Adsorption in Nanoporous Materials close to Saturation Conditions. Journal of Chemical Theory and Computation 2017, 13, 3326-3339.

(18) Tian, Y.; Yan, C.; Jin, Z. Characterization of Methane Excess and Absolute Adsorption in Various Clay Nanopores from Molecular Simulation. Scientific Reports 2017, 7, 12040.

(19) Zhou, C.; Hall, F.; Gasem, K. A.; Robinson, R. L. J. Predicting Gas Adsorption Using Two-Dimensional Equations of State. Industrial $\backslash \&$ Engineering Chemistry Research 1994, 33, 1280-1289.

(20) Pan, Z.; Connell, L. The Representation of Multi-Component Adsorption in Reservoir Simulation of CO2 Sequestration in Coal and Enhanced Coalbed Methane Recovery. International Coalbed Methane Symposium. Tuscaloosa, Alabama, Paper 05092005.

(21) Gasem, K. A. M.; Robinson Jr, R. L.; Fitzgerald, J. E.; Pan, Z.; Sudibandriyo, M. Sequestering Carbon Dioxide in Coalbeds. 2003.

(22) Gasem, K. A. M.; Pan, Z.; Mohammad, S.; Robinson Jr, R. L. Two-Dimensional Equation-of-State Modeling of Adsorption of Coalbed Methane Gases. In Carbon dioxide sequestration in geological media-State of the science: AAPG Studies in Geology; M. Grobe, J. C. Pashin, and R. L. Dodge, Ed.; AAPG Special Volumes, 2009.

(23) Payne, H. K.; Sturdevant, G. A.; Leland, T. W. Improved Two-Dimensional Equation of State to Predict Adsorption of Pure and Mixed Hydrocarbons. Industrial $\backslash \&$ Engineering Chemistry Fundamentals 1968, 7, 363-374.

(24) Glandt, E. D.; Myers, A. L.; Fitts, D. D. Two-Dimensional Equations of State: A Comparison with Experiment. The Journal of Chemical Physics 1979, 70, 4243-4247.

(25) Cuadros, F.; Mulero, A.; Morala, L.; Gómez-Serrano, V. Isosteric Heat for Monolayer Adsorption Obtained from Two-Dimensional Equations of State. Langmuir 2001, 17, $1576-1581$.

(26) Pan, Z. Modeling Gas Adsorptions Using Two-Dimensional Equations of State, 2004.

(27) Bakhtyari, A.; Mofarahi, M. A New Approach in Predicting Gas Adsorption Isotherms and Isosteric Heats Based on Two-Dimensional Equations of State. Arabian Journal for Science and Engineering 2019, 1-14. 
(28) Sudibandriyo, M. Generalized Ono-Kondo Lattice Model for High Pressure Adsorption on Carbon Adsorbents, 2003.

(29) Gibbs, J. W. On the Equilibrium of Heterogeneous Substances. Transactions of the Connecticut Academy of Arts and Sciences 1879.

(30) Van Ness, H. C. Adsorption of Gases on Solids. Review of Role of Thermodynamics. Industrial $\backslash \&$ Engineering Chemistry Fundamentals 1969, 8, 464-473.

(31) Abbott, M. M. Cubic Equations of State. AIChE Journal 1973, 19, 596-601.

(32) Fotoohi, F.; Amjad-Iranagh, S.; Golzar, K.; Modarress, H. Predicting Pure and Binary Gas Adsorption on Activated Carbon with Two-Dimensional Cubic Equations of State (2-D EOSs) and Artificial Neural Network (ANN) Method. Physics and Chemistry of Liquids 2016, 54, 281-302.

(33) Redlich, O.; Kwong, J. N. S. On the Thermodynamics of Solutions. V. An Equation of State. Fugacities of Gaseous Solutions. Chemical Reviews 1949, 44, 233-244.

(34) Soave, G. Equilibrium Constants from a Modified Redlich-Kwong Equation of State. Chemical Engineering Science 1972, 27, 1197-1203.

(35) Peng, D.-Y.; Robinson, D. B. A New Two-Constant Equation of State. Industrial $\backslash \&$ Engineering Chemistry Fundamentals 1976, 15, 59-64.

(36) Van der Waals, J. D.; Rowlinson, J. S. On the Continuity of the Gaseous and Liquid States; Courier Corporation, 2004.

(37) Koretsky, M. D. Engineering and Chemical Thermodynamics; Wiley New York, 2004; Vol. 2.

(38) Sandler, S. I. Chemical, Biochemical, and Engineering Thermodynamics; John Wiley I\& Sons, 2017.

(39) Leahy-Dios, A.; Firoozabadi, A. Unified Model for Nonideal Multicomponent Molecular Diffusion Coefficients. AIChE Journal 2007, 53, 2932-2939.

(40) Hoteit, H.; Firoozabadi, A. Numerical Modeling of Diffusion in Fractured Media for Gas-Injection and-Recycling Schemes. SPE Journal 2009, 14, 323-337.

(41) Moortgat, J.; Firoozabadi, A. Three-Phase Compositional Modeling with Capillarity in Heterogeneous and Fractured Media. SPE Journal 2013, 18, 1-150.

(42) Babaei, M.; Mu, J.; Masters, A. J. Impact of Variation in Multicomponent Diffusion Coefficients and Salinity in CO2-EOR: A Numerical Study Using Molecular Dynamics Simulation. Journal of Petroleum Science and Engineering 2018, 162, 685696. 
(43) Kärger, J.; Ruthven, D. M.; Theodorou, D. N. Diffusion in Nanoporous Materials; John Wiley $\backslash \&$ Sons, 2012.

(44) Kazemi, M.; Takbiri-Borujeni, A. Selective Adsorption and Transport Diffusion of $\mathrm{CO} 2-\mathrm{CH} 4$ Binary Mixture in Carbon-Based Organic Nanopores. In SPE Western Regional Meeting; 2017.

(45) Xiong, J.; Liu, X.; Liang, L.; Zeng, Q. Adsorption of Methane in Organic-Rich Shale Nanopores: An Experimental and Molecular Simulation Study. Fuel 2017, 200, 299315.

(46) Peigney, A.; Laurent, C.; Flahaut, E.; Bacsa, R. R.; Rousset, A. Specific Surface Area of Carbon Nanotubes and Bundles of Carbon Nanotubes. Carbon 2001, 39, 507-514.

(47) Gadipelli, S.; Guo, Z. X. Graphene-Based Materials: Synthesis and Gas Sorption, Storage and Separation. Progress in Materials Science 2015, 69, 1-60.

(48) Knapp, H. Z. S.; Langhorst, R. Vapor-Liquid Equilibria for Mixtures of Low Boiling Substances. Pt. 3. Ternary Systems. 1989, 6.

(49) Fateen, S.-E. K.; Khalil, M. M.; Elnabawy, A. O. Semi-Empirical Correlation for Binary Interaction Parameters of the Peng-Robinson Equation of State with the van Der Waals Mixing Rules for the Prediction of High-Pressure Vapor-Liquid Equilibrium. Journal of Advanced Research 2013, 4, 137-145.

(50) Sudibandriyo, M.; Mohammad, S. A.; Robinson, R. L.; Gasem, K. A. M. Ono-Kondo Lattice Model for High-Pressure Adsorption: Pure Gases. Fluid Phase Equilibria 2010, 299, 238-251.

(51) Ramdharee, S.; Muzenda, E.; Belaid, M. A Review of the Equations of State and Their Applicability in Phase Equilibrium Modeling. In International Conference on Chemical and Environmental Engineering; 2013.

(52) Lopez-Echeverry, J. S.; Reif-Acherman, S.; Araujo-Lopez, E. Peng-Robinson Equation of State: 40 Years through Cubics. Fluid Phase Equilibria 2017, 447, 39-71.

(53) Twu, C. H.; Coon, J. E.; Bluck, D. Comparison of the Peng- Robinson and SoaveRedlich- Kwong Equations of State Using a New Zero-Pressure-Based Mixing Rule for the Prediction of High-Pressure and High-Temperature Phase Equilibria. Industrial I\& Engineering Chemistry Research 1998, 37, 1580-1585.

(54) Ghanbari, M.; Ahmadi, M.; Lashanizadegan, A. A Comparison between PengRobinson and Soave-Redlich-Kwong Cubic Equations of State from Modification Perspective. Cryogenics 2017, 84, 13-19.

(55) Ji, L.; Zhang, T.; Milliken, K. L.; Qu, J.; Zhang, X. Experimental Investigation of Main Controls to Methane Adsorption in Clay-Rich Rocks. Applied Geochemistry 2012, 27, 2533-2545. 
(56) Liu, D.; Yuan, P.; Liu, H.; Li, T.; Tan, D.; Yuan, W.; He, H. High-Pressure Adsorption of Methane on Montmorillonite, Kaolinite and Illite. Applied Clay Science 2013, 85, $25-30$.

(57) Gu, Y.; Ding, W.; Yin, S.; Yin, M.; Xiao, Z. Adsorption Characteristics of Clay Minerals in Shale. Petroleum Science and Technology 2018, 36, 108-114.

(58) Shen, W.; Li, X.; Xu, Y.; Sun, Y.; Huang, W. Gas Flow Behavior of Nanoscale Pores in Shale Gas Reservoirs. Energies 2017, 10, 751.

(59) Zhang, L.; Shan, B.; Zhao, Y.; Du, J.; Chen, J.; Tao, X. Gas Transport Model in Organic Shale Nanopores Considering Langmuir Slip Conditions and Diffusion: Pore Confinement, Real Gas, and Geomechanical Effects. Energies 2018, 11, 223.

(60) Wang, S.; Feng, Q.; Zha, M.; Javadpour, F.; Hu, Q. Supercritical Methane Diffusion in Shale Nanopores: Effects of Pressure, Mineral Types, and Moisture Content. Energy I\& Fuels 2017, 32, 169-180.

(61) Nazari Moghaddam, R.; Jamiolahmady, M. Slip Flow in Porous Media. Fuel 2016, $173,298-310$.

(62) Zhang, J.; Liu, K.; Clennell, M. B.; Dewhurst, D. N.; Pervukhina, M. Molecular Simulation of CO2-CH4 Competitive Adsorption and Induced Coal Swelling. Fuel 2015, 160, 309-317.

(63) Kowalczyk, P.; Gauden, P. A.; Terzyk, A. P.; Furmaniak, S.; Harris, P. J. F. Displacement of Methane by Coadsorbed Carbon Dioxide Is Facilitated in Narrow Carbon Nanopores. The Journal of Physical Chemistry C 2012, 116, 13640-13649.

\section{Nomenclature}

\begin{tabular}{|c|c|c|}
\hline Symbol & Definitions & Units \\
\hline$A$ & Area of Adsorbent & $\mathrm{m}^{2}$ \\
\hline$A A D$ & Average Absolute Deviation & $\%$ \\
\hline$A R S D$ & Average Relative Standard Deviation & $\%$ \\
\hline$c$ & Concentration of Fluid & $\operatorname{mol~m}{ }^{-3}$ \\
\hline$c_{a}$ & Total Number of Moles Adsorbed per Unit Area & mol m $\mathrm{m}^{-2}$ \\
\hline$d_{e}$ & External Diameter of Carbon Nanotube & $\mathrm{nm}$ \\
\hline$d_{s-s}$ & Adjacent Distance between Layers of Nanotube Wall & $\mathrm{nm}$ \\
\hline$D_{c}$ & Corrected (Maxwell-Stefan) Diffusivity & $\mathrm{m}^{2} \mathrm{~s}^{-1}$ \\
\hline$D_{t}$ & Transport (Fick’s) Diffusivity & $\mathrm{m}^{2} \mathrm{~s}^{-1}$ \\
\hline$f_{i}^{a}$ & Fugacity of Component $i$ in Adsorbed Phase & bar \\
\hline$f_{i}^{g}$ & Fugacity of Component $i$ in Bulk Phase & bar \\
\hline$f_{i}^{c a l}$ & Calculated Fugacity from Regressed Parameters & bar \\
\hline
\end{tabular}




\begin{tabular}{|c|c|c|}
\hline$f_{i}^{e x p}$ & Experimental Molecular Simulation Fugacity & bar \\
\hline$f_{1}^{g}$ & Fugacity of Component 1 in Bulk Phase & bar \\
\hline$f_{2}^{g}$ & Fugacity of Component 2 in Bulk Phase & bar \\
\hline$k$ & Henry Constant for Pure Component Isotherm & mol bar ${ }^{-1} \mathrm{~m}^{-2}$ \\
\hline$k_{B}$ & Boltzmann Constant & $\mathrm{kg} \mathrm{m}^{2} \mathrm{~s}^{-2} \mathrm{~K}^{-1}$ \\
\hline$k_{1}$ & Henry Constant for Component 1 & mol bar ${ }^{-1} \mathrm{~m}^{-2}$ \\
\hline$k_{2}$ & Henry Constant for Component 2 & mol bar ${ }^{-1} \mathrm{~m}^{-2}$ \\
\hline$k_{12}$ & Binary Interaction Parameter & Dimensionless \\
\hline$M_{r}$ & Molecular Mass & $\mathrm{g} \mathrm{mol}^{-1}$ \\
\hline$m_{a b s}$ & Absolute Adsorption & mol \\
\hline$m_{e x}$ & Excess Adsorption & mol \\
\hline$n$ & Number of Layers within Nanotube Wall & Dimensionless \\
\hline$n^{a}$ & Total Number of Moles Adsorbed & mol \\
\hline$n_{i}^{a}$ & Number of Moles of Component $i$ Adsorbed & mol \\
\hline$n_{j}^{a}$ & Number of Moles of Component $j$ Adsorbed & mol \\
\hline$N_{a}$ & Avogadro's Constant & $\mathrm{mol}^{-1}$ \\
\hline$N_{p}$ & Number of Data Points for Regression & Dimensionless \\
\hline$P$ & Total Pressure of System & bar \\
\hline$P_{c}$ & Critical Pressure & bar \\
\hline$r$ & Radius of Capillary & $\mathrm{nm}$ \\
\hline$R$ & Ideal Gas Constant & $\mathrm{kg}^{2} \mathrm{~m}^{2} \mathrm{~s}^{-2} \mathrm{~mol}^{-1} \mathrm{~K}^{-1}$ \\
\hline$R M S E$ & Root Mean Square Error & bar \\
\hline$S S A_{M W N T}$ & Specific Surface Area of Multi-wall Nanotube & $\mathrm{m}^{2} \mathrm{~g}^{-1}$ \\
\hline$S S A_{S W}$ & Specific Surface Area of Single Wall Nanotube & $\mathrm{m}^{2} \mathrm{~g}^{-1}$ \\
\hline$S_{M}$ & Relative Error & Dimensionless \\
\hline$T$ & Temperature of Adsorption System & $\mathrm{K}$ \\
\hline$T_{0}$ & Boiling Point of Fluid at Atmospheric Pressure & $\mathrm{K}$ \\
\hline$T_{c}$ & Critical Temperature & $\mathrm{K}$ \\
\hline$V_{a}$ & Volume of Adsorbed Phase & $\mathrm{m}^{3}$ \\
\hline $\bar{x}$ & Mean Value of $\alpha, \beta$ or $k$ & Parameter Dependent \\
\hline$x_{i}$ & Mole Fraction of Component $i$ in Adsorbate Phase & Dimensionless \\
\hline$x_{1}$ & Mole Fraction of Component 1 in Adsorbate Phase & Dimensionless \\
\hline$x_{2}$ & Mole Fraction of Component 2 in Adsorbate Phase & Dimensionless \\
\hline$y_{1}$ & Mole Fraction of Component 1 in Bulk Phase & Dimensionless \\
\hline$y_{2}$ & Mole Fraction of Component 2 in Bulk Phase & Dimensionless \\
\hline$y_{1, \text { calc }}$ & Calculated Bulk Phase Mole Fraction of Component 1 & Dimensionless \\
\hline$y_{1, \text { calc }}$ & Calculated Bulk Phase Mole Fraction of Component 2 & Dimensionless \\
\hline
\end{tabular}


$y_{1, \text { spec }} \quad$ Specified Bulk Phase Mole Fraction of Component 1

$y_{2, \text { spec }} \quad$ Specified Bulk Phase Mole Fraction of Component 2

Z Compressibility Factor

$\alpha \quad$ Regressed Parameter Analogous to $a$ in Cubic EoS

$\alpha_{1} \quad$ Regressed Pure Component $1 \alpha$ Adsorption Isotherm

$\alpha_{2} \quad$ Regressed Pure Component $2 \alpha$ Adsorption Isotherm

$\alpha_{m} \quad$ Mixed $\alpha$ Parameter for Binary System

$\alpha_{12} \quad \alpha$ Parameter for Unlike Interactions

$\beta \quad$ Regressed Parameter Analogous to $b$ in Cubic EoS

$\beta_{1} \quad$ Regressed Component $1 \beta$ Adsorption Isotherm

$\beta_{2} \quad$ Regressed Component $2 \beta$ Adsorption Isotherm

$\beta_{m} \quad$ Mixed $\beta$ Parameter for Binary System

$\gamma \quad$ Thermal Expansion Coefficient

$\Gamma \quad$ Thermodynamic Factor for Pure Component

$\Gamma_{11}$ Thermodynamic Factor of Component 1 in Binary System

$\Gamma_{22}$ Thermodynamic Factor of Component 2 in Binary System

$\varepsilon \quad$ EoS Dependent Parameter (RK, SRK, PR)

$\varepsilon_{f f}{ }^{*} \quad$ Lennard Jones Fluid Potential Well Depth

$\varepsilon_{s s}{ }^{*} \quad$ Lennard Jones Solid Potential Well Depth

$\varepsilon_{f s} \quad$ Fluid-Solid Potential Well Depth

$\eta \quad$ EoS Dependent Parameter (RK, SRK, PR)

$\lambda \quad$ EoS Dependent Parameter (RK, SRK, PR)

$\rho_{a} \quad$ Density of Adsorbed Phase

$\rho_{b} \quad$ Density of Bulk Phase

$\rho_{m c} \quad$ Calculated Adsorbate Phase Density

$\rho_{s} \quad$ Atomic Density of Adsorbent

$\sigma \quad$ Molar Surface Area (Area per unit Amount Adsorbed)

$\sigma_{f f} \quad$ Lennard Jones Fluid Molecule Collision Diameter

$\sigma_{f s} \quad$ Fluid-Solid Molecule Collision Diameter

Maximum Surface Density of Adsorbate at the Normal Boiling

$\sigma_{m, 0}^{\prime}$ Point of the Fluid

$\sigma_{s s} \quad$ Lennard Jones Solid Molecule Collision Diameter

$\sigma_{x} \quad$ Standard Deviation Value of $\alpha, \beta$ or $k$

$\phi_{1} \quad$ Fugacity Coefficient of Component 1 in Bulk Phase

$\phi_{2} \quad$ Fugacity Coefficient of Component 2 in Bulk Phase

$\omega \quad$ Acentric Factor

$\nabla \quad$ Gradient
Dimensionless

Dimensionless

Dimensionless

$\mathrm{kg} \mathrm{m}^{4} \mathrm{~mol}^{-2} \mathrm{~s}^{-2}$

$\mathrm{kg} \mathrm{m}^{4} \mathrm{~mol}^{-2} \mathrm{~s}^{-2}$

$\mathrm{kg} \mathrm{m}^{4} \mathrm{~mol}^{-2} \mathrm{~s}^{-2}$

$\mathrm{kg} \mathrm{m}^{4} \mathrm{~mol}^{-2} \mathrm{~s}^{-2}$

$\mathrm{kg} \mathrm{m}^{4} \mathrm{~mol}^{-2} \mathrm{~s}^{-2}$

$\mathrm{m}^{2} \mathrm{~mol}^{-1}$

$\mathrm{m}^{2} \mathrm{~mol}^{-1}$

$\mathrm{m}^{2} \mathrm{~mol}^{-1}$

$\mathrm{m}^{2} \mathrm{~mol}^{-1}$

$\mathrm{K}^{-1}$

Dimensionless

Dimensionless

Dimensionless

Dimensionless

$\mathrm{kg} \mathrm{m}^{2} \mathrm{~s}^{-2}$

$\mathrm{kg} \mathrm{m}^{2} \mathrm{~s}^{-2}$

$\mathrm{kg} \mathrm{m}^{2} \mathrm{~s}^{-2}$

Dimensionless

Dimensionless

$\mathrm{kg} \mathrm{m}^{-3}$

$\mathrm{kg} \mathrm{m}^{-3}$

$\mathrm{kg} \mathrm{m}^{-3}$

$\AA^{-2}$

$\mathrm{m}^{2} \mathrm{~mol}^{-1}$

$\mathrm{nm}$

$\mathrm{nm}$

$\mathrm{m}^{2} \mathrm{~mol}^{-1}$

$\mathrm{nm}$

Parameter Dependent

Dimensionless

Dimensionless

Dimensionless

Dimensionless 